\title{
COMMUNICATIONS
}

\section{INFLUENCE OF THE INTRA-OCULAR PRESSURE ON THE FORMATION OF THE AQUEOUS HUMOUR AND THE OUTFLOW RESISTANCE IN THE LIVING EYE*}

\author{
BY
}

\author{
MAURICE E. LANGHAM \\ From the Medical Research Council, England, and the Howe Laboratory of Ophthalmology, Harvard \\ University Medical School
}

THIS study deals with the problem of the regulation of the intra-ocular pressure and the influence of pressure on the formation and the resistance to outflow of the aqueous humour. The main experimental approach has been to analyse the relationship between the steady state intra-ocular pressure and varied rates of flow of fluid through the anterior chamber of living and dead eyes. In the experiments on living animals, the normal rate of flow of aqueous humour was augmented by infusions of fluid directly into the anterior chamber. Provided that the factors determining the normal intraocular pressure remain constant, it is evident that the equilibrium pressure in the eye will increase proportionately with the rate at which fluid is infused into the eye. In the experiments to be described, a linear relationship was found in dead eyes over a wide range of pressures but not in eyes of living animals.

The results of these studies were consistent with a concept of homeostatic reflex activity in the eye which acted to minimize changes in the intra-ocular pressure, by altering either aqueous humour formation or the outflow resistance. This possibility was examined in further experiments in which the normal intra-ocular pressure and dynamics were modified experimentally. These included procedures for decreasing the rate of aqueous humour formation and the outflow resistance, and experiments in which either the nervous or the vascular supply to the eye was altered.

Recently, the problem of the influence of pressure on aqueous humour dynamics has taken on additional significance following the introduction of tonography (Grant, 1950, 1951) for the measurement of the outflow facility and aqueous humour formation. This technique has been widely used in experimental and clinical studies, and its validity rests on the assumption that a moderate increase in intra-ocular pressure $(10$ to $15 \mathrm{~mm}$. $\mathrm{Hg})$ does not 
significantly disturb aqueous humour formation or outflow resistance. The outflow resistance is calculated from the rate of change in the intra-ocular volume when a tonometer is placed on the eye; the weight of the tonometer increases the pressure in the eye and this causes an increased outflow of aqueous humour accompanied by a gradual fall in the intra-ocular pressure. The validity of this assumption is examined in this paper.

\section{Methods}

Male and female rabbits used in this study weighed from 1.8 to $3.5 \mathrm{~kg}$.; approximately 75 per cent were New Zealand white and the remainder were pigmented. Animals were anaesthetized with Nembutal $(0.5$ to $1.0 \mathrm{ml} . / \mathrm{kg}$.) or Urethane $(0.8$ to $1.75 \mathrm{~g} . / \mathrm{kg}$.) given intravenously.

The intra-ocular and blood pressures were recorded with electrical pressure transducers made either by Statham Instruments (California, U.S.A.) or Sanborn Instruments (Waltham, Mass., U.S.A.). The Statham transducer (P23 G) had a volume displacement of $0.01 \mu \mathrm{l} . / 100 \mathrm{~mm}$. $\mathrm{Hg}$, and the Sanborn $267 \mathrm{~B}$ transducer a volume displacement of $0.05 \mu 1 . / 100 \mathrm{~mm}$. $\mathrm{Hg}$. The electrical outputs of the transducers were fed into Sanborn Instruments model 150-1100 carrier preamplifiers and the Sanborn $150 \mathrm{M}$ rectilinear multi-channel pen-recorder. The maximal sensitivity of the apparatus was $1 \mathrm{~cm}$. deflection for 1 to $2 \mathrm{~mm}$. $\mathrm{Hg}$.

The constant injection machine used in this study incorporated a series of eight gears, allowing the speed to be changed over a range of $25: 1$, and the rate of injection could be further modified by the use of syringes of different sizes. To reduce backlash when changing gears, a clutch and an on-off cam were built into the drive mechanism and in this way a gear change could be effected within 5 sec. The friction drive of the apparatus was found adequate to maintain a constant rate of injection with a recipient pressure greater than $100 \mathrm{~mm}$. $\mathrm{Hg}$.

A four-way block with four taps was made to inter-connect the infusion machine, the pressure reservoir, the transducer, and the anterior chamber, either simultaneously or separately. The block was made of Perspex, and metal cones shaped to take a standard syringe needle were sealed into the outlets. The taps, also made from Perspex, were slightly tapered and fitted closely into the block; they were greased with silicone grease at the start of each experiment. The taps and connexions were found to be leakproof to saline under pressure of at least $100 \mathrm{~mm} . \mathrm{Hg}$ and one has been in continuous use for 12 months without need of replacement.

The concentration of protein was determined by a micro-nephelometric technique.

Experimental Procedure.-The animal was anaesthetized and the femoral artery cannulated with a polythene tube prefilled with heparinized saline. The animal was then laid on its stomach with its head facing forwards. Before insertion the recording needle was connected to a reservoir of saline at $25 \mathrm{~mm}$. $\mathrm{Hg}$. To bring the needle into the anterior chamber, the superior rectus muscle was gripped firmly with toothed forceps and the needle was pushed obliquely through the cornea from the limbal region until the bevel lay in front of the pupil. Directly the needle was in position the tap to the reservoir was turned off and the eye was connected to the transducer. The connexions between the eye and the Perspex 
block and the manometer were kept as short as possible, and in the present experiments were about 4 inches long. At the completion of the experiment a sample of aqueous humour was withdrawn for protein analysis.

\section{Results}

It was important to the main purpose of this study to know the normal intra-ocular pressure of living rabbits and the pressure in the eyes immediately after death. Numerous attempts to measure the pressure in the living eye by a manometric technique have been made, but the majority of these experiments were carried out under grossly unphysiological conditions. Leber (1876) introduced needles into the eyes of a small series of conscious rabbits given no local anaesthetic and recorded pressures of 18 to $30 \mathrm{~mm}$. $\mathrm{Hg}$. In similar experiments, the intra-ocular pressure has been reported to vary from 15 to $30 \mathrm{~mm}$. $\mathrm{Hg}$ in rabbits given curare (Wessely, 1908), chloroform (Stocker, 1887), or locally-applied cocaine (Niesnamoff, 1896). Except for the few experiments of Wessely on normal rabbits, no measurements of blood pressure were made, and in view of the painful procedures employed, the small number of animals, and the known depressor action of curare on the blood and intra-ocular pressures (Henderson and Starling, 1904), the results are unlikely to indicate the true intra-ocular pressure. Recently Guerry (1951) has published the results of manometric measurements of the intra-ocular pressure in eighteen rabbits anaesthetized with Nembutal, and the writer has calculated that these rabbits had a mean intra-ocular pressure of $18.8 \pm 1.0 \mathrm{~mm}$. $\mathrm{Hg}$ (arithmetic mean \pm standard error).

In the course of the present studies manometric measurement of the intraocular pressure was made immediately after insertion of the recording needle into the anterior chamber, and several recordings were also taken of the blood and intra-ocular pressures at the time of death. In 36 adult rabbits anaesthetized with Urethane, the mean pressures in the eyes and femoral arteries were $20.6 \pm 0.57$ and $114 \pm 1.4 \mathrm{~mm}$. $\mathrm{Hg}$ respectively. No correlation was found between body weight and intra-ocular pressure in this series of rabbits.

In similar experiments on 22 rabbits lightly anaesthetized with Nembutal, the mean intra-ocular pressure was $17 \cdot 2 \pm 0.63 \mathrm{~mm}$. $\mathrm{Hg}$, which is significantly lower than that in the animals anaesthetized with Urethane $(p<0.001)$. The femoral arterial blood pressure recorded in four of these rabbits had a mean value of $105 \pm 6 \mathrm{~mm}$. $\mathrm{Hg}$. The intra-ocular pressure in this series of rabbits agreed well with the values reported by Guerry (1951).

The pressures in pairs of eyes were found to be essentially the same. In twelve rabbits the mean pressures in the left and right eyes were $20 \cdot 0 \pm 0.39$ and $20 \cdot 3 \pm 0.38 \mathrm{~mm}$. $\mathrm{Hg}$ respectively, and in the same animals the mean pressure difference between the two eyes was $0.96 \pm 0.20 \mathrm{~mm}$. Hg. 
A representative record of the blood and intra-ocular pressures of a rabbit killed by an intravenous injection of Nembutal is shown in Fig. 1. The intra-ocular pressure fell rapidly immediately after death to approximately $10 \mathrm{~mm}$. Hg, and then continued to fall slowly until a value of approximately $6 \mathrm{~mm}$. Hg was reached 10 to $15 \mathrm{~min}$. later. Over longer periods of time the pressure fell to 1 to $2 \mathrm{~mm}$. $\mathrm{Hg}$ below this value; in three rabbits the intraocular pressures were 4 to $5 \mathrm{~mm}$. $\mathrm{Hg}$ one hour after death.
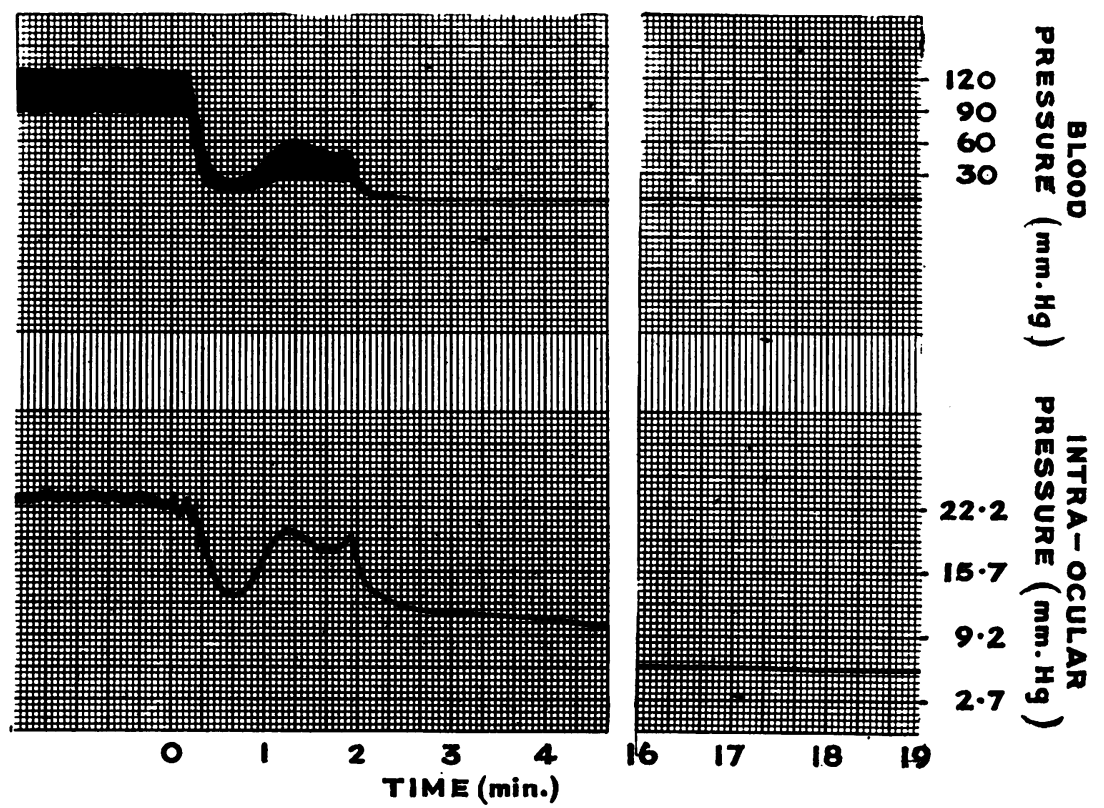

Fig. 1.-Intra-ocular pressure and femoral artery blood pressure in an adult rabbit at death induced by an intravenous injection of Nembutal.

Pressure decay curves from the eyes of four rabbits $10 \mathrm{~min}$. after death are shown in Fig. 2 (opposite).

Similar observations of the intra-ocular pressure 15 to $20 \mathrm{~min}$. after death were made in a series of 29 eyes, and the mean final pressure was $7 \cdot 0 \pm 0.37 \mathrm{~mm}$. $\mathrm{Hg}$. This value is in general agreement with the observations and conclusions of Henderson and Starling (1904) and Duke-Elder (1927) that the intra-ocular pressure of cats and dogs fell to about $10 \mathrm{~mm} . \mathrm{Hg}$ at death and remained at this value until post-mortem changes set in.

Infusion Studies.-In these experiments, the intra-ocular pressure was recorded during the injection of saline or aqueous humour into the anterior chamber. The normal rate of flow of the aqueous humour is generally accepted to be 1 to 2 per cent. min. ${ }^{-1}$ (see Langham, 1958a) and on this basis the absolute rate of flow in the rabbits used in this study was 2 to 


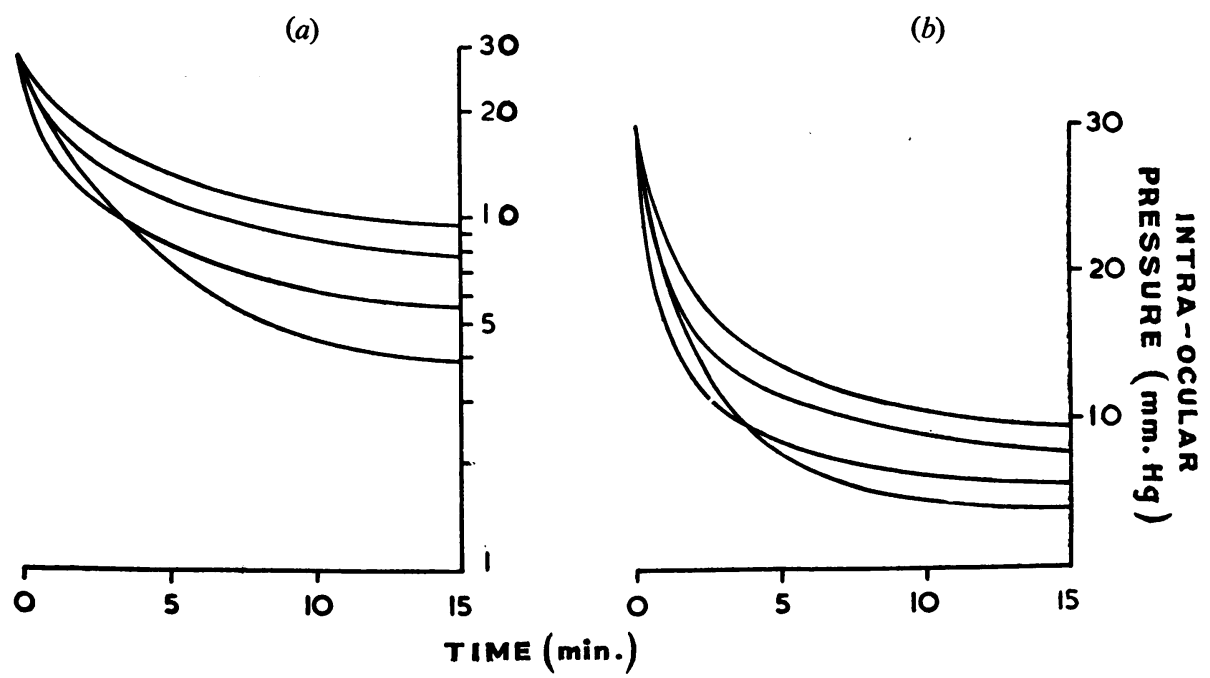

FIG. 2. - Rate of fall in intra-ocular pressure in eyes of four rabbits $10 \mathrm{~min}$. after death ( $t=0 \mathrm{~min}$.). At $t=0 \mathrm{~min}$. saline was run into the eye to bring the pressure to $30 \mathrm{~mm}$. $\mathrm{Hg}$; the decay curves are plotted logarithmically $(a)$ and arithmetically $(b)$.

$4 \mu \mathrm{l}$. min. ${ }^{-1}$. In comparison, the lowest rate of infusion used in these experiments was $0.5 \mu 1$. min. ${ }^{-1}$.

First, the effect of the needle itself on the stability of the intra-ocular pressure was investigated. In four animals a 27-gauge needle (external diameter $0.4 \mathrm{~mm}$.) connected to the recording manometer was introduced through the cornea into the anterior chamber. In three of these animals the blood pressure remained constant throughout the experimental period of 60 min., and the mean intra-ocular pressure also showed no significant change (less than 1 to $2 \mathrm{~mm}$. $\mathrm{Hg}$ ). During longer experimental periods the intra-ocular pressure tended to fall independently of the blood pressure. The blood and intra-ocular pressures of the.fourth rabbit fell by 30 and $4 \mathrm{~mm}$. $\mathrm{Hg}$ respectively during the experimental period. When larger needles were used (e.g. 15 gauge, diameter $0.6 \mathrm{~mm}$.), the intra-ocular pressure fell by 2,0 , and $4 \mathrm{~mm}$. $\mathrm{Hg}$ in $60 \mathrm{~min}$. in three animals. In these experiments changes in the permeability of the blood-aqueous barrier were assessed from quantitative analysis of the protein in the aqueous humour. In three eyes, one hour after the introduction of 27-gauge needles, the concentrations of protein in samples of aqueous humour were 15,25 , and $17 \mathrm{mg}$. $/ 100 \mathrm{ml}$., and in the corresponding control eyes 12,16 , and $14 \mathrm{mg} . / 100 \mathrm{ml}$. With 15 -gauge needles, the concentrations of protein in the aqueous humour after $60 \mathrm{~min}$. were 50 and $73 \mathrm{mg} . / 100 \mathrm{ml}$. in two eyes and 9 and $12 \mathrm{mg} . / 100 \mathrm{ml}$. in the corresponding control eyes. In view of these findings, 27-gauge needles were used in all infusion studies to minimize disturbance to the eye.

The change in the intra-ocular pressure when saline was infused into the 
anterior chamber of a living rabbit is shown in a typical record in Fig. 3.

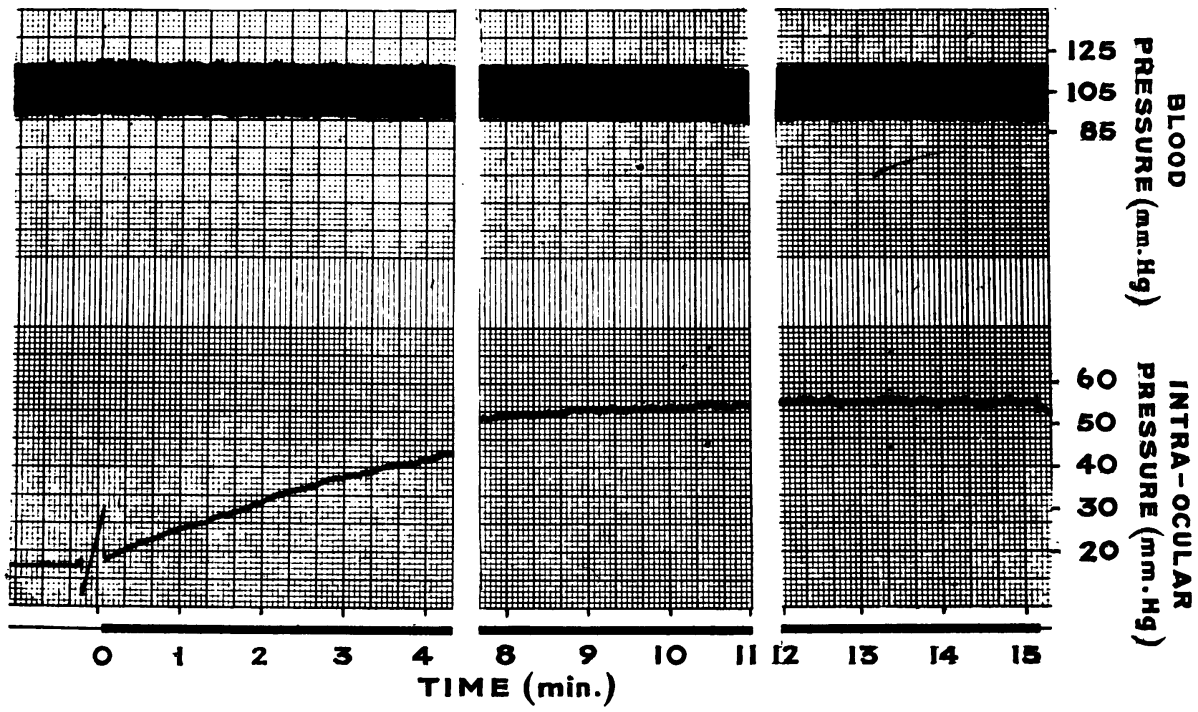

FIG. 3.-Intra-ocular pressure during an infusion of saline phosphate $(\mathrm{pH} \mathrm{7.4)}$ at the rate of $5 \mu \mathrm{l}$. min. ${ }^{-1}$ into the anterior chamber of an anaesthetized rabbit (wt. $2.6 \mathrm{~kg}$.). Injection was begun at $t=0 \mathrm{~min}$.

The infusion led to an immediate rise in the intra-ocular pressure until a new steady state was attained in 10 to $15 \mathrm{~min}$. In similar experiments infusions of 0.5 to $7.5 \mu \mathrm{l}$. min. ${ }^{-1}$ were made, and again the intra-ocular pressure increased and closely approached a steady state in approx. $15 \mathrm{~min}$.

Continuation of the infusions over longer experimental periods caused variations in the intra-ocular pressure. In two rabbits infusions of $2 \cdot 3 \mu 1$. min. ${ }^{-1}$ were continued for $45 \mathrm{~min}$., and in one the intra-ocular pressure increased from an initial value of 21 to $28 \mathrm{~mm}$. $\mathrm{Hg}$ in $15 \mathrm{~min}$. and remained at this level during the remaining $30 \mathrm{~min}$. of the experiment. In the other rabbit a similar rise in intra-ocular pressure was observed but there was a subsequent fall of $5 \mathrm{~mm}$. Hg. When the infusion was stopped the pressure fell below the pre-infusion value and showed no signs of recovery in the ensuing $20 \mathrm{~min}$.; in addition, the aqueous humour of this eye was found to be moderately plasmoid. In two other experiments, infusions of $5 \mu 1 . \mathrm{min}^{-1}$ were continued for $45 \mathrm{~min}$. The intra-ocular pressures increased in a similar manner and extent to that shown in Fig. 3. In one rabbit the pressure began to fall again after $30 \mathrm{~min}$., while in the second there was a spontaneous increase in the intra-ocular pressure after $35 \mathrm{~min}$. After the infusion was stopped the intra-ocular pressures did not return to their initial levels.

While these preliminary experiments showed that even small increases in the normal rate of flow of aqueous humour through the anterior chamber increased the intra-ocular pressure, they also indicated that the intra-ocular pressure did not increase proportionately with the infusion rate. Thus, in 
one rabbit having an intra-ocular pressure of $19 \mathrm{~mm}$. $\mathrm{Hg}$, an infusion of $2 \mu \mathrm{l}$. min. ${ }^{-1}$ caused an increase of $5 \mathrm{~mm}$. $\mathrm{Hg}$ and an infusion of $5 \mu \mathrm{l}$. min..$^{-1}$ caused an increase of $23 \mathrm{~mm}$. $\mathrm{Hg}$.

Several attempts were made to obtain sufficient experimental data by this method, in order to define the relationship between the steady state intraocular pressure and the infusion rates in individual eyes, but these failed owing to the instability of the eye. In all cases the basal intra-ocular pressure fell during the course of the experiment and it was impossible to reproduce results. As a consequence a different experimental approach was tried and this proved to give reproducible results.

In this procedure a saline reservoir was used to bring the intra-ocular pressure near its steady state value for each infusion rate. If the altered pressure was still below the equilibrium value, it continued to increase, whereas if the pressure was above the equilibrium value it would fall. By recording two convergent curves, the steady state intra-ocular pressure for a given rate of infusion could be defined in 2 to $3 \mathrm{~min}$. compared with the 15 to $20 \mathrm{~min}$. taken to derive the steady state pressure by the previous technique. A record of infusion experiments carried out in this way is shown in Fig. 4, where the pressure scale has been condensed to illustrate the records obtained at different infusion rates. In actual experiments greater accuracy was obtained by increasing the sensitivity of the recording system. With this increased sensitivity the steady state pressure could be evaluated to within $\pm 2 \mathrm{~mm}$. Hg. In separate experiments the value of the steady state pressure obtained by this technique agreed closely with that obtained by the previous method.

(1)

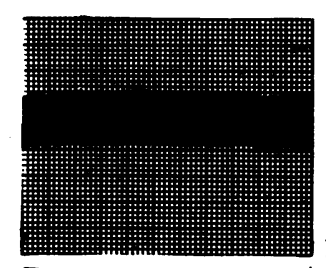

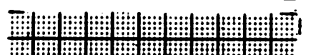

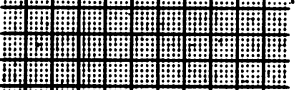

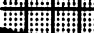
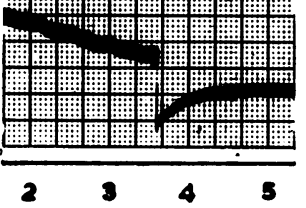

(2)
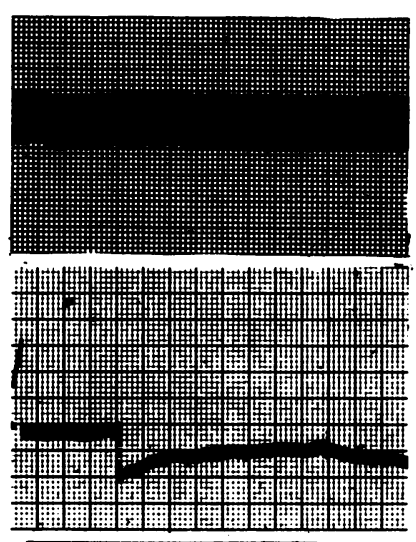

7
(3)

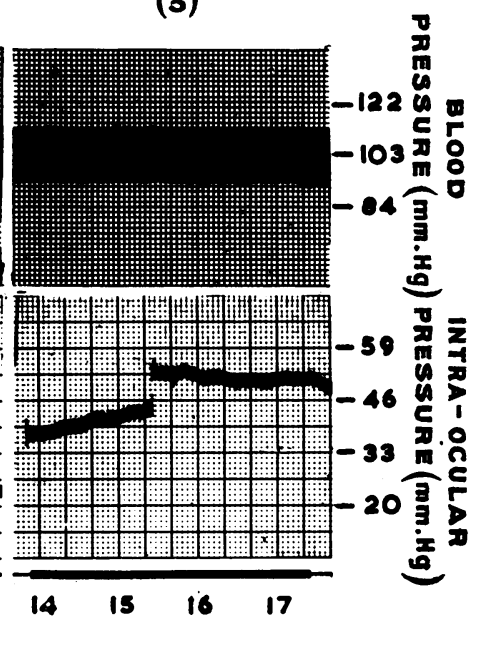

Fig. 4.-Technique used in determining steady state intra-ocular pressure for different infusions. Breaks in records show time when eye was connected momentarily to saline phosphate reservoir to alter intra-ocular pressure. (1) Normal intra-ocular pressure. (2) and (3) Steady state pressure for infusions of 3.7 and $5 \mu \mathrm{l}$. min. ${ }^{-1}$ respectively. 
The application of this technique to determine the influence of different infusion rates on the steady state intra-ocular pressure in a rabbit will be considered in detail. The results of a representative experiment are shown in Fig. 5(a) (opposite). The normal intra-ocular pressure was recorded at the beginning, middle, and end of the infusion studies, and the whole experiment was completed within $30 \mathrm{~min}$. The three values of the normal intra-ocular pressure varied by less than $1 \mathrm{~mm}$. $\mathrm{Hg}$, and the mean blood pressure remained constant $(100 \mathrm{~mm} . \mathrm{Hg})$. At the end of the experiment the aqueous humour was removed from both the experimental and the untouched eye, and the concentrations of protein were found to be $15 \mathrm{and} .18 \mathrm{mg} . / 100 \mathrm{ml}$. respectively.

Similar infusion studies were made on more than fifty normal eyes from forty rabbits. The relationship between steady state pressure and infusion in all but five of these eyes showed positive curves, and in all eyes the intraocular pressure increased from its normal value of $20 \mathrm{~mm}$. $\mathrm{Hg}$ to approximately $60 \mathrm{~mm}$. $\mathrm{Hg}$ for an infusion of 6 to $9 \mu \mathrm{l}$. min. ${ }^{-1}$. The results in 26 normal eyes of animals anaesthetized with Urethane are shown in Table I and Fig. $5(d)$. It will be seen that the steady state intra-ocular pressure increased proportionately for the infusions ranging from 3 to $6 \mu 1$. min. ${ }^{-1}$, while below this range the effect on pressure became disproportionately small as the infusion rate approached zero. In the five remaining eyes of this series, the relationship between pressure and infusion was approximately linear.

\section{TABLE I}

MEAN STEADY STATE INTRA-OCULAR PRESSURE FOR DIFFERENT RATES OF INFUSION OF SALINE PHOSPHATE (pH 7.4) INTO THE.ANTERIOR CHAMBER OF RABBITS ANAESTHETIZED WITH URETHANE

\begin{tabular}{c|c}
\hline Infusion Rate $\left(\mu 1 . \mathrm{min}^{-1}\right)$ & Steady State Intra-ocular Pressure $(\mathrm{mm} . \mathrm{Hg})$ \\
\cline { 2 - 2 } & \\
0.0 & $21.3 \pm 0.49(26)$ \\
1.0 & $23.1 \pm 0.57(26)$ \\
2.0 & $26.3 \pm 0.82(26)$ \\
3.0 & $30.8 \pm 1 \cdot 17(26)$ \\
4.0 & $38.5 \pm 1.90(26)$ \\
5.0 & $46.2 \pm 2.35(26)$ \\
6.0 & $56.3 \pm 3.14(26)$ \\
\hline
\end{tabular}

Eyes of individual rabbits were found to react in the same way to infusions of saline phosphate, and the result of an infusion study on one pair of eyes is recorded in Fig. 5(c). Similar results were obtained in experiments on the individual eyes of three other rabbits. Finally, a comparison of fresh bovine aqueous humour and saline phosphate as the infusion medium was made in pairs of eyes in two rabbits, and it was found that the two fluids gave essentially similar results.

The effects of these infusions on living eyes showed that the parameters determining the normal intra-ocular pressure did not remain constant when the pressure in the eyes was increased. The question then arose whether this reaction was specific to the living eye, and similar infusion studies were therefore made on dead eyes. 


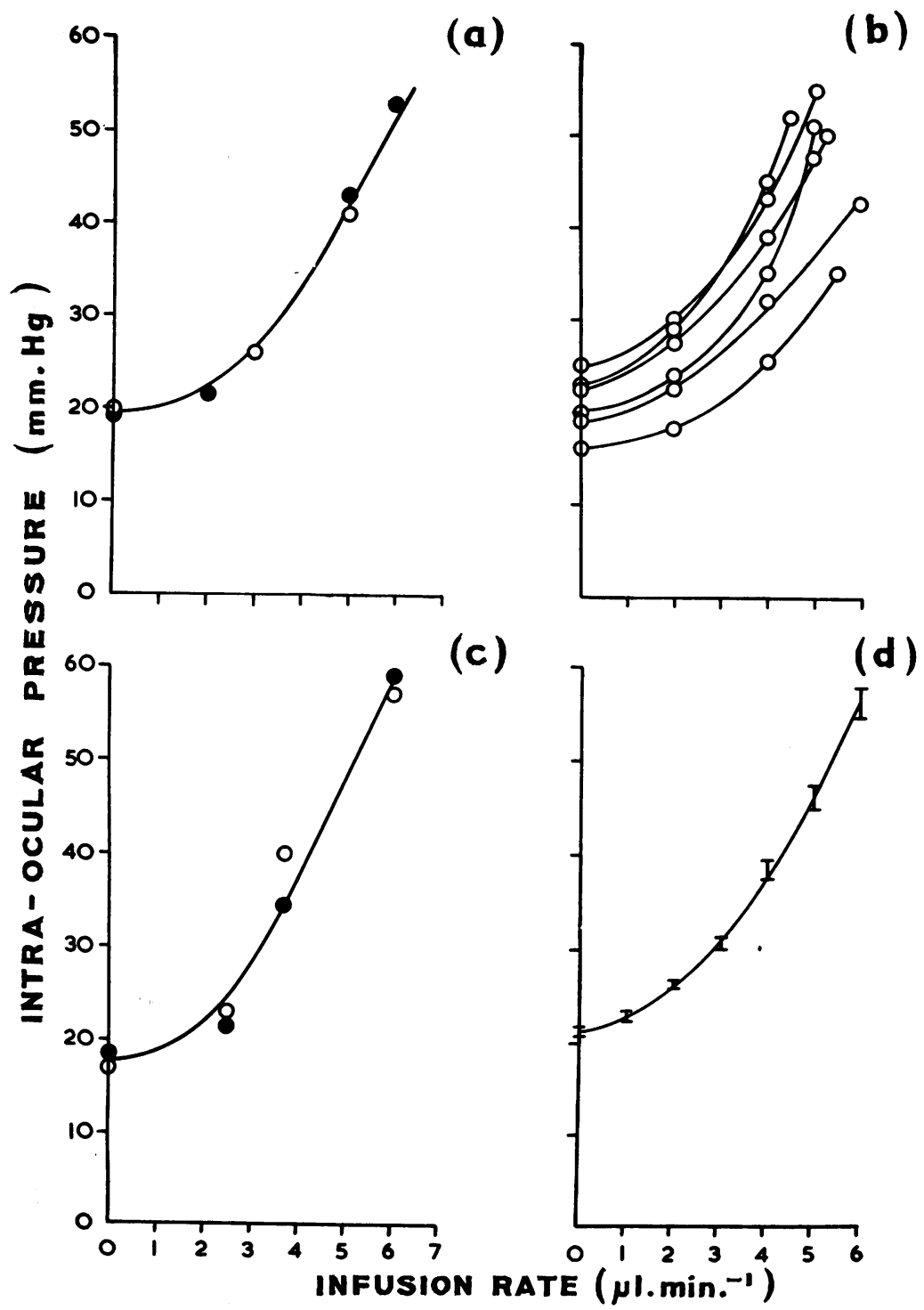

FIG. 5.-Relationship between steady state intra-ocular pressure and infusion rates in rabbits anaesthetized with Urethane.

(a) An individual rabbit in which infusions were carried out first in descending order (- $)$ and then in ascending order ( $\mathrm{O}-\mathrm{O})$;

(b) Records relating steady state intra-ocular pressure and infusion rates in six rabbits;

(c) Results of similar experiments on the left (-—) and right $(\mathrm{O}-\mathrm{O})$ eyes of one rabbit;

(d) Summary of results of infusion studies on 26 normal adult rabbits. Each bar represents the mean pressure \pm standard error for each infusion. 
The first series of experiments was made on eyes left in the dead animal. The animals were killed and left for $20 \mathrm{~min}$. to allow the eyes to cool to room temperature. The results of the first four experiments (Fig. 6(a), opposite) indicated that the intra-ocular pressure in conditions of steady state increased approximately proportionately with the rate of flow of fluid into the eye over a wide range of pressures.

The procedure of leaving the eyes in the dead animal was, however, dropped in favour of an alternative technique, for it was found that the results varied with time after death. Thus, in each of these four experiments, the slope of the curve for the second eye, which had been left in the dead animal for approximately $90 \mathrm{~min}$., was less than that for the first eye. To eliminate this variable factor it was decided to use eyes enucleated from living rabbits. The first eye was enucleated and placed in a bed of cotton wool moistened with saline, and the infusion study was begun $20 \mathrm{~min}$. after enucleation; after completion of the infusion study the second eye was enucleated and treated in a similar manner. By this technique the results in pairs of eyes were found to agree closely (Fig. $6(b))$. The mean curve relating the intra-ocular pressure and the rate of infusion in a series of eyes enucleated from eight living rabbits is shown in Fig. 6(c) (see also Table II).

TABLE II

MEAN STEADY STATE INTRA-OCULAR PRESSURE FOR DIFFERENT RATES OF INFUSION OF SALINE PHOSPHATE (pH 7.4) INTO THE ANTERIOR CHAMBER OF FRESHLY ENUCLEATED RABBIT EYES

\begin{tabular}{|c|c|}
\hline Infusion Rate $\left(\mu \mathrm{l} . / \mathrm{min}^{-1}\right)$ & Steady State Intra-ocular Pressure (mm. Hg) \\
\hline $\begin{array}{r}0.0 \\
3.0 \\
5.0 \\
7.5 \\
10 \cdot 0\end{array}$ & $\begin{array}{c}7 \cdot 0 \pm 1 \cdot 5 \quad(8) \\
13 \cdot 8 \pm 2 \cdot 5 \quad(8) \\
25 \cdot 3 \pm 0 \cdot 95 \text { (8) } \\
41 \cdot 9 \pm 1 \cdot 84 \text { (8) } \\
59 \cdot 7 \pm 2 \cdot 6 \quad(8)\end{array}$ \\
\hline
\end{tabular}

The curve is similar to that found in the above experiments made on eyes of dead rabbits. The slope of the curve was approximately constant over a wide range of pressures (10 to $50 \mathrm{~mm}$. $\mathrm{Hg}$ ), and was equivalent to an outflow resistance of $6.8(\mathrm{~mm} . \mathrm{Hg}) \mathrm{min} . \mu 1 .^{-1}$ These experiments were made at $20^{\circ} \mathrm{C}$. and, if a correction is made for the change in viscosity of water with temperature, the value becomes $4.7(\mathrm{~mm}$. $\mathrm{Hg}) \mathrm{min} . \mu \mathrm{l}^{-1}$ at $37^{\circ} \mathrm{C}$. In tonographic studies it has been customary to express the outflow resistance in terms of a coefficient of facility where this is defined as reciprocal resistance, and on this basis the above resistance corresponds to an outflow facility of $0.21 \mu 1 .(\mathrm{mm} . \mathrm{Hg})^{-1} \mathrm{~min}^{-1}$ This is less than the mean value of $0.37 \mu 1$. $(\mathrm{mm} . \mathrm{Hg})^{-1}$ min. $^{-1}$ found in perfusion studies of dead rabbit eyes by Becker and Constant (1956) and the mean values of 0.34 and $0.30 \mu \mathrm{l} .(\mathrm{mm} . \mathrm{Hg})^{-1}$ min..$^{-1}$ measured by tonography in anaesthetized rabbits by Becker and Constant (1956) and Kornbluth and Linnér (1955) respectively. 
A comparison of saline phosphate and aqueous humour as the infusion fluid was made in pairs of enucleated eyes, and no significant difference was found between the two eyes from one animal. Finally, a comparison was made of infusion curves in living and dead eyes from four individual animals. The result of a typical experiment is shown in Fig. $6(d)$.

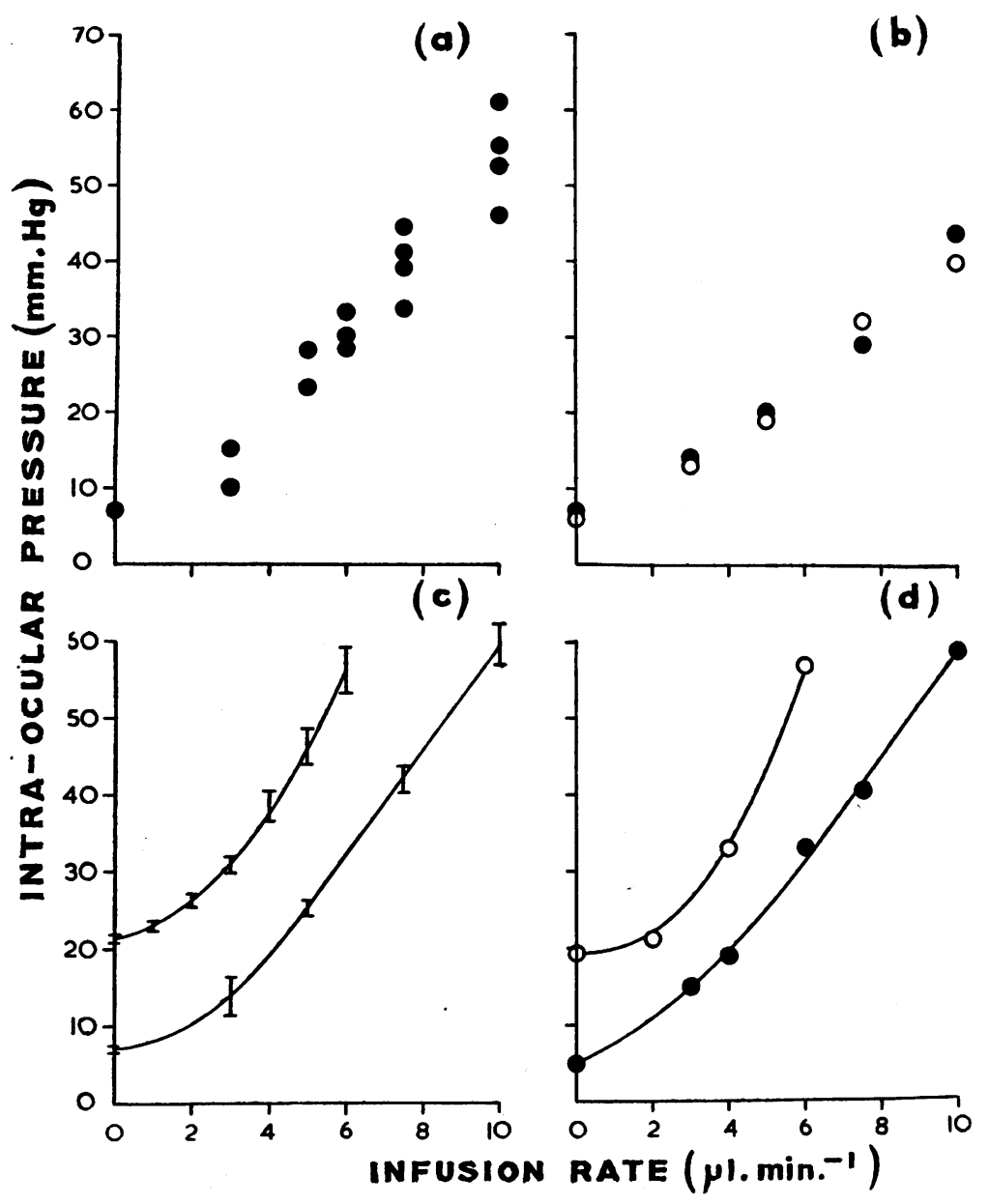

FIG. 6.-Relationship between steady state intra-ocular pressure and infusion rate in eyes after death.

(a) Records from eyes left in situ in four rabbits; these studies were begun 20 min. after death.

(b) Agreement in two enucleated eyes from the same animal; studies in each eye were begun $20 \mathrm{~min}$. after enucleation from the living animal.

(c) Mean curve from infusion studies on freshly enucleated eyes from eight rabbits (lower curve) and from living rabbits (upper curve).

(d) Typical record of results on the living $(\mathrm{O}-\mathrm{O})$ and enucleated ( - - ) eyes of the same animal.

All experiments on dead eyes were made at room temperature. 
Effect of Intra-ocular Infusions on the Pressure in the Contralateral Eye.It has been reported by several investigators that, when a tonometer is left on the eye for several minutes, the pressure falls approximately $2 \mathrm{~mm} . \mathrm{Hg}$ in the contralateral eye. Prijot and Stone (1956) found that, when this was done on rabbits, the outflow resistance, measured tonographically, and the episcleral venous pressure remained unchanged in the contralateral eye, and they therefore concluded that the observed fall in the intra-ocular pressure was due to a decreased rate of aqueous humour formation. In the present study several experiments were made in which the intra-ocular pressures of both eyes were recorded during the infusion of fluid into one eye. Infusions of 0.5 to $5 \mu 1 . \mathrm{min}^{-1}$ for $10 \mathrm{~min}$. caused no change in the intra-ocular pressure in the contralateral eyes of four rabbits.

In the same rabbits the pressure in one eye was increased rapidly to between 30 and $40 \mathrm{~mm}$. $\mathrm{Hg}$, but again no pressure change was observed in the contralateral eye. A typical result is shown in Fig. 7.

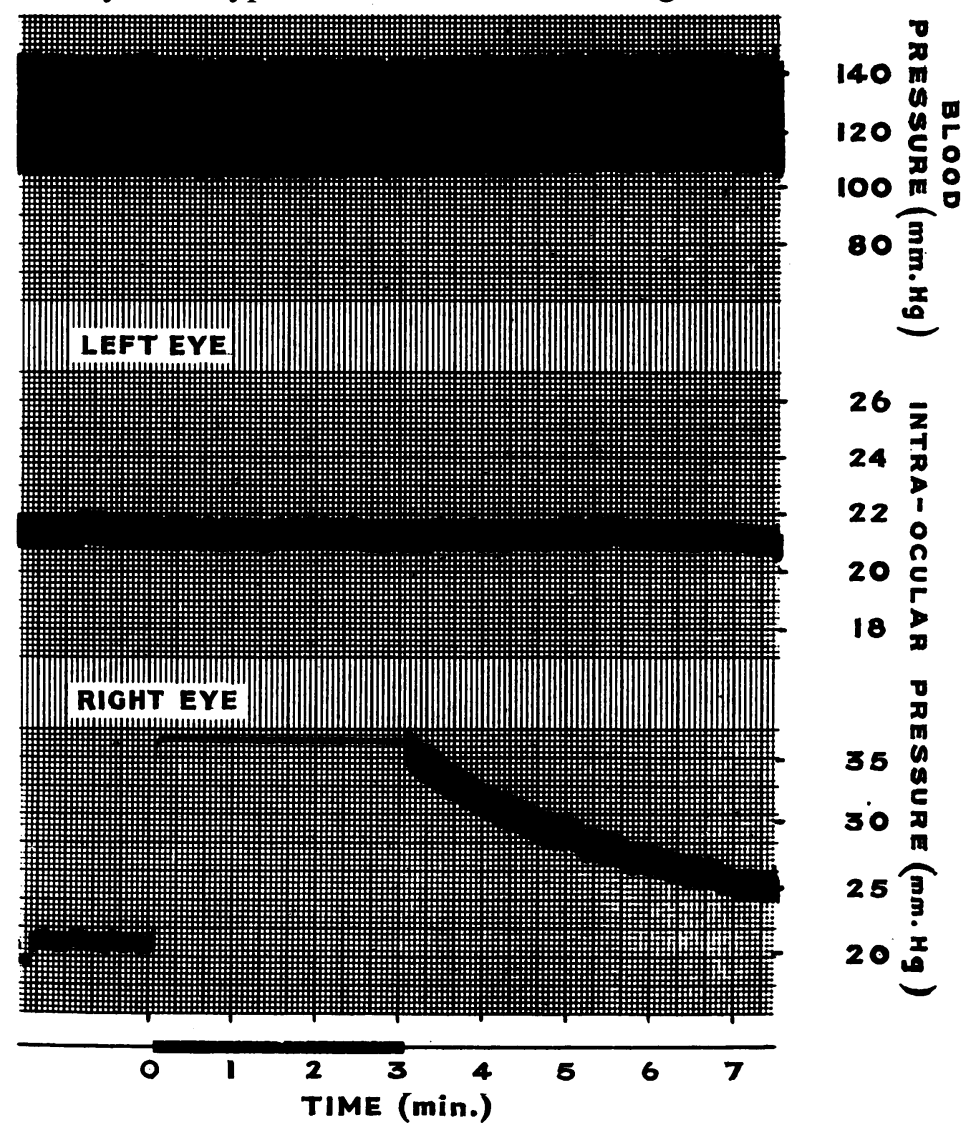

FIG. 7.-Effect of increased intra-ocular pressure on pressure in the contralateral eye of a rabbit anaesthetized with Urethane. The anterior chamber of the right eye (lower record) was connected to a pressure reservoir at $37 \mathrm{~mm}$. $\mathrm{Hg}$ for $3 \mathrm{~min}$., and then the tap was turned off and the pressure allowed to fall spontaneously. There was no significant change in the intra-ocular pressure in the left eye (middle record). 
Factors influencing the Relationship between the Intra-ocular Pressure and Flow in Living Rabbits

The preceding observations on the relationship between intra-ocular pressure and infusions of saline into the anterior chamber of living and dead eyes were consistent with the hypothesis that an increase of pressure in the eye causes a compensatory decrease in either the rate of aqueous humour formation or that of the outflow resistance. If true, this would be a valuable step forward in our understanding of the regulation of the intra-ocular pressure, but to test this hypothesis directly it would be necessary to isolate the process of aqueous humour formation from that of drainage. Unfortunately, no way of doing this under physiological conditions has yet been found. It was, however, considered possible to assess the validity of this hypothesis by observing what happened to the relationship between the steady state pressure and infusion rates under conditions calculated to stimulate homeostatic reactions in the eye. In the order to be considered, the experimental procedures were as follows:

(a) Intravenous injection of the carbonic anhydrase inhibitor acetazoleamide (2- acetylamino-1, 3, 4 thiadiazole 5 sulphonamide. Diamox, Lederle Laboratories);

(b) Ligation of the common carotid artery;

(c) Section of the preganglionic cervical sympathetic fibres;

(d) Intra-ocular injection of the enzyme hyaluronidase.

(a) Intravenous Injection of the Carbonic Anhydrase Inhibitor, Acetazoleamide.-The object of these experiments was to study eyes in which the intraocular pressure had been decreased by a reduction in the rate of formation of aqueous humour. It is well known that inhibitors of the enzyme carbonic anhydrase cause a rapid fall in the intra-ocular pressure of man and animals when given by mouth or by intravenous injection, and that this change is due to a decrease in the rate of formation of aqueous humour (Becker, 1955; Langham and Lee, 1957; Langham, 1958b). It has been found that the pressure tends to increase with continued administration of the drug, and Becker and Middleton (1955) reported that this was due to a slow compensatory increase in the outflow resistance. On the other hand, this secondary rise in pressure could be due to a recovery in the rate of aqueous humour formation, for Langham and Lee (1957) found that the fluorescein appearance time returned to normal within 3 hours in spite of continued administration of acetazoleamide. As the initial fall in pressure takes place within the first 20 minutes, it was thought worthwhile to make infusion studies both during this time and several hours after the first injection of acetazoleamide.

In a series of five rabbits infusion studies were made first on one eye and then on the contralateral eye 20 to $40 \mathrm{~min}$. after an intravenous injection of 
acetazoleamide $(50 \mathrm{mg} . / \mathrm{kg}$.). The intra-ocular pressures in the control eyes were $25,20,26,19$, and $19 \mathrm{~mm}$. $\mathrm{Hg}$, and in the corresponding experimental eyes $22,16,22,13$, and $16 \mathrm{~mm}$. $\mathrm{Hg}$. The curves relating pressure and infusion rates in the experimental eyes differed significantly from the curves in the control eyes, for in three eyes the pressure/infusion curve was linear while in the remaining two experimental eyes it showed positive curvature but less than in the control eyes; examples of the two types of results are shown in Fig. 8.

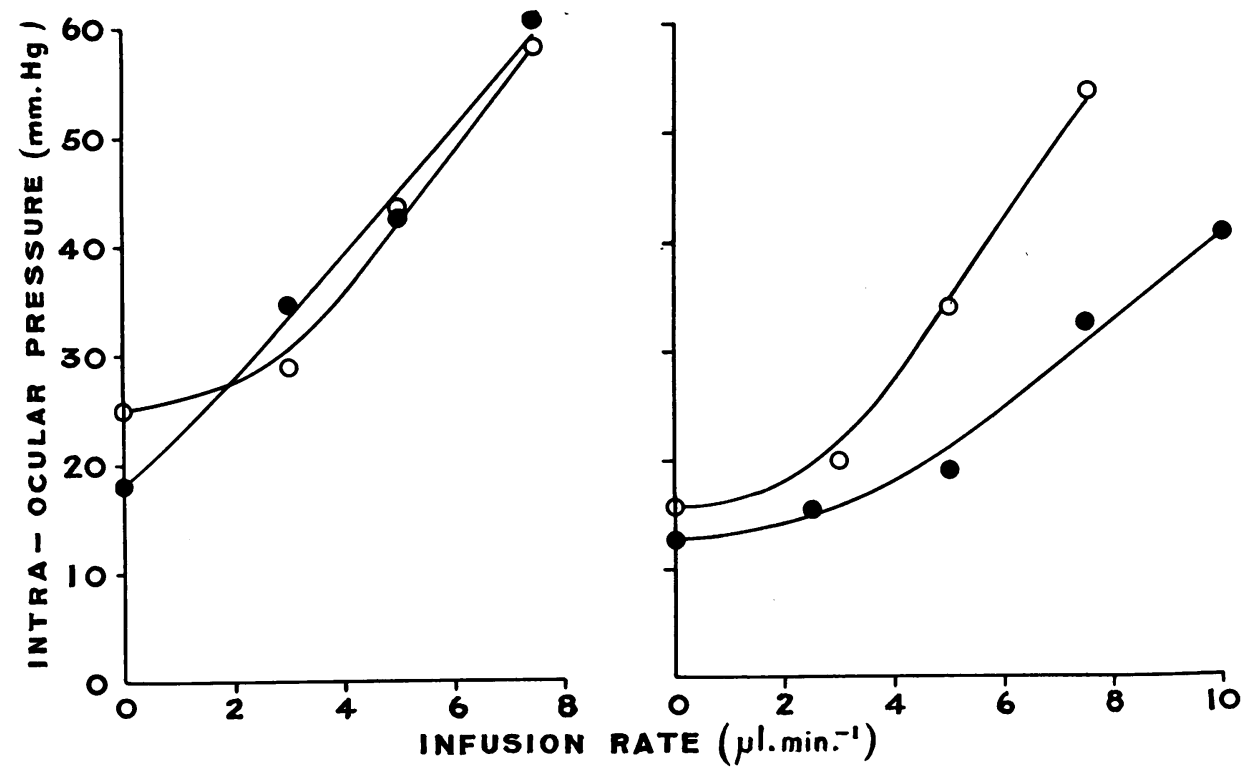

FIG. 8.-Immediate effect of acetazoleamide on relationship between steady state intra-ocular pressure and infusion rate in anaesthetized rabbits.

Infusion studies on the first eyes $(\mathrm{O}-\mathrm{O})$ were completed before the intravenous injection of acetazoleamide $(25 \mathrm{mg} . / \mathrm{kg}$.). Those on the second eyes $(\bullet-\bullet)$ were started $15 \mathrm{~min}$. later.

In two further experiments acetazoleamide was given to the conscious animals $(50 \mathrm{mg} . / \mathrm{kg}$.) and the infusion studies were started $60 \mathrm{~min}$. later. All four eyes were studied and the pressure was found to increase in proportion to the rate of infusion.

In a second series of five rabbits acetazoleamide was given hourly and the animals were anaesthetized $300 \mathrm{~min}$. after the initial injection; the dosage was adequate to sustain an effective inhibitory concentration throughout the experimental period. The mean intra-ocular pressure in the ten eyes of the five rabbits was $21 \cdot 1 \pm 0.77 \mathrm{~mm}$. $\mathrm{Hg}$, and the mean femoral arterial blood pressure was $107 \mathrm{~mm}$. Hg. This pressure is higher than the mean intra-ocular pressure observed at 30 to $60 \mathrm{~min}$. in the previous series, and is not significantly different from the mean pressure of $20 \cdot 6 \pm 0.57$ found in the control series. Results from pairs of eyes agreed closely and in all five animals there was a linear relation between the intra-ocular pressure and the infusion rates (see Fig. 9, opposite). 


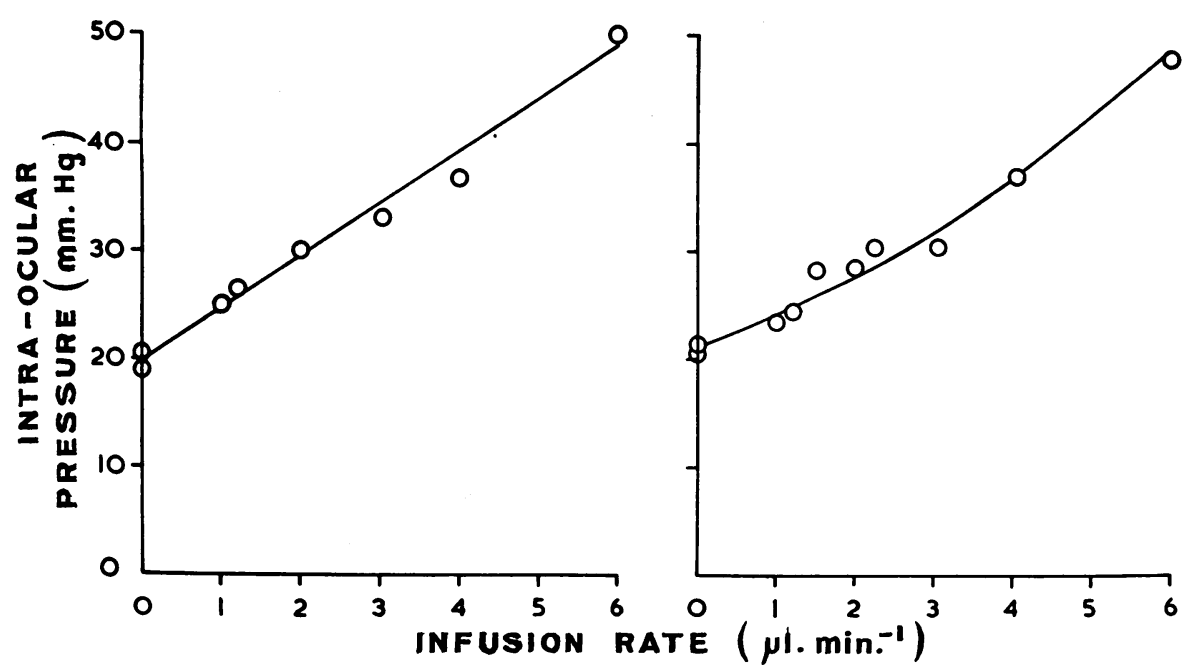

FIG. 9.-Effect of continued administration of acetazoleamide on relationship between steady state intra-ocular pressure and infusion rate in two rabbits. The drug was injected intravenously into the conscious animals in an initial dose of $50 \mathrm{mg} . / \mathrm{kg}$. followed by an hourly injection of $25 \mathrm{mg} . / \mathrm{kg}$.

$300 \mathrm{~min}$. after the initial injection the animals were anaesthetized and infusion studies made on both eyes $(0-0)$.

(b) Unilateral Ligation of the Common Carotid Artery.-Bárány (1947a) reported that unilateral ligation of the common carotid artery of rabbits caused a fall in blood pressure in the ophthalmic artery from a normal value of $100 \mathrm{~mm}$. $\mathrm{Hg}$ to approximately $67 \mathrm{~mm}$. $\mathrm{Hg}$, and a decrease of $3.5 \mathrm{~mm}$. $\mathrm{Hg}$ in the intra-ocular pressure. In manometric studies on anaesthetized rabbits, Davson and Matchett (1951) reported that the intra-ocular pressure fell rapidly by an average of $7 \mathrm{~mm}$. $\mathrm{Hg}$. The effect of this operation on intra-ocular dynamics remains in doubt; on the one hand, from determinations of the turnover rate of $\mathrm{Na}^{24}$ in the aqueous humour, it has been argued that the rate of formation of aqueous humour is not changed significantly (Bárány, 1947b) or is reduced by only 7 per cent. (Davson and Matchett, 1951), while on the other hand Kornbluth and Linnér (1955) concluded from tonographic studies that there was a decrease of approximately 60 per cent. in the rate of formation of aqueous humour and an increase of 30 per cent. in the outflow resistance.

A possible explanation of these different conclusions may be found in the fact that the observations of Bárány and those of Davson and Matchett were made soon after ligation of the artery, while those of Kornbluth and Linnér were made 24 hours after the operation. It was therefore decided to make infusion studies both immediately and 24 hours after the operation.

In three anaesthetized rabbits, infusion studies were made on one eye and the carotid artery on the contralateral side was then tied and an infusion study initiated $15 \mathrm{~min}$. later. In two of these rabbits ligation of the artery 
caused an immediate fall in the intra-ocular pressure, but in the third (see Fig. 10) no immediate fall took place. At $15 \mathrm{~min}$. the pressures were approximately steady at 2,2 , and $3 \mathrm{~mm}$. below normal. In all of these experiments the curves relating pressure to infusion rates were similar in the control and experimental eyes.
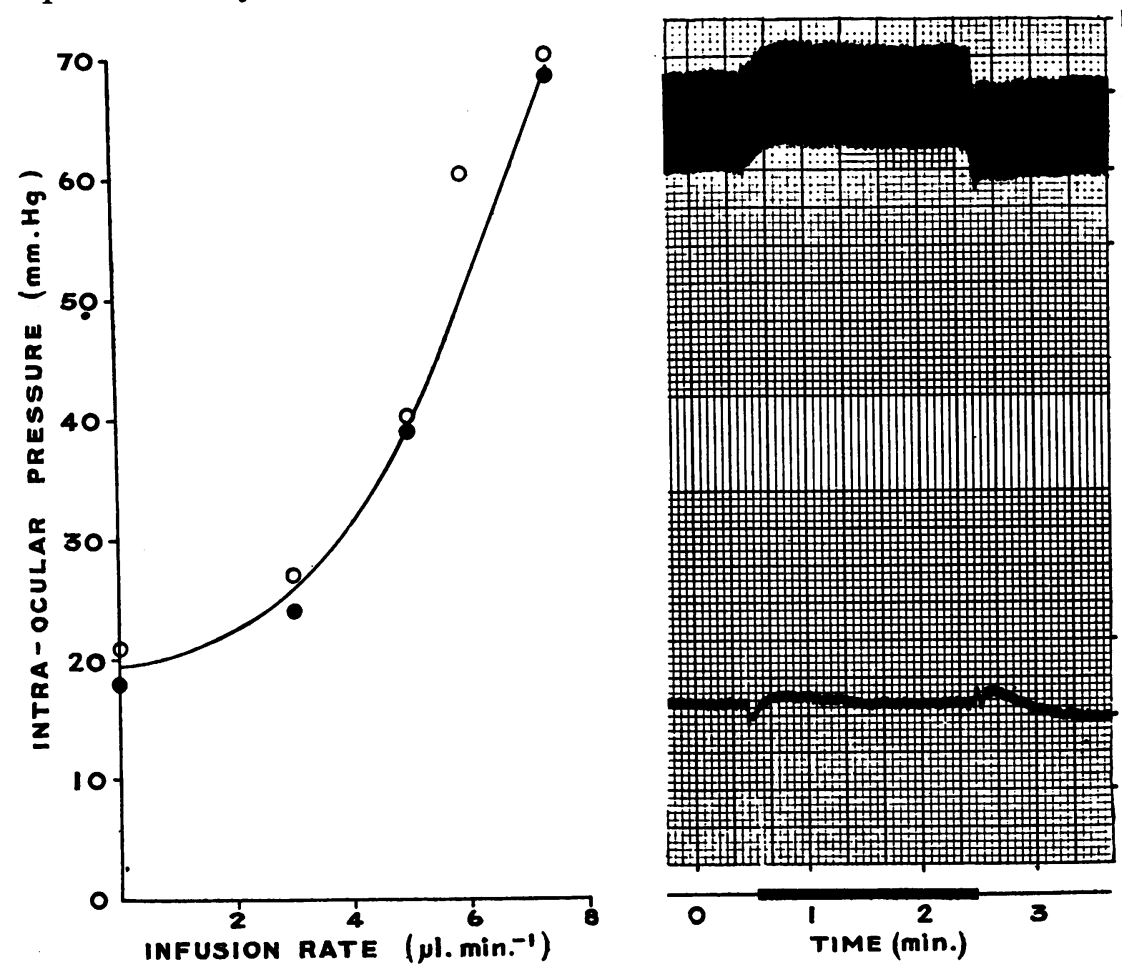

Fig. 10.-Immediate effect of unilateral carotid ligation on relationship between steady state intra-ocular pressure and infusion rate in an adult rabbit anaesthetized with Urethane.

An infusion study on one eye $(\mathrm{O}-\mathrm{O})$ was completed before ligation of the contralateral common carotid artery and an infusion study on the second eye ( $\bullet$ ) was begun $20 \mathrm{~min}$. later.

The record on the right shows the immediate effect of clamping and unclamping the homolateral carotid artery on the intra-ocular pressure in this rabbit.

In four further rabbits, infusion studies were made 24 hours after the ligation of one common carotid artery. The intra-ocular pressures in the control and experimental eyes were $17 \cdot 5,24 \cdot 0,22 \cdot 5$, and $20 \mathrm{~mm}$. $\mathrm{Hg}$ and $12 \cdot 5,20,15$, and $14.5 \mathrm{~mm}$. $\mathrm{Hg}$ respectively, and the mean femoral arterial blood pressure was $115 \mathrm{~mm}$. $\mathrm{Hg}$. The results of infusion studies in the control eyes were the same as in normal eyes, but the results in the experimental eyes were significantly different. In three of the four rabbits the steady state intra-ocular pressure in the experimental eyes increased proportionately with the infusion rates (Fig. 11, opposite). In the fourth eye, which had a very low intra-ocular pressure $(12 \mathrm{~mm}$. $\mathrm{Hg})$, the intra-ocular pressure increased very little for moderate increments in the infusion rate. 
(c) Unilateral Section of the Preganglionic Cervical Sympathetic Fibres.Davson and Matchett (1951) reported that section of the preganglionic sympathetic fibres of rabbits caused an immediate rise in the intra-ocular pressure in 26 out of 49 animals and no pressure change in the remaining 23 animals. In rabbits studied 24 hours after the operation, Linnér and Prijot (1957) found the intra-ocular pressure to be equal in pairs of eyes, and they concluded from tonographic studies that there was no change in either outflow resistance or aqueous humour formation. The present series of experiments was made immediately and 24 hours after section of the nerve; $1 \mathrm{~cm}$. of the nerve was removed 2 to $3 \mathrm{~cm}$. proximal to the superior cervical ganglion.
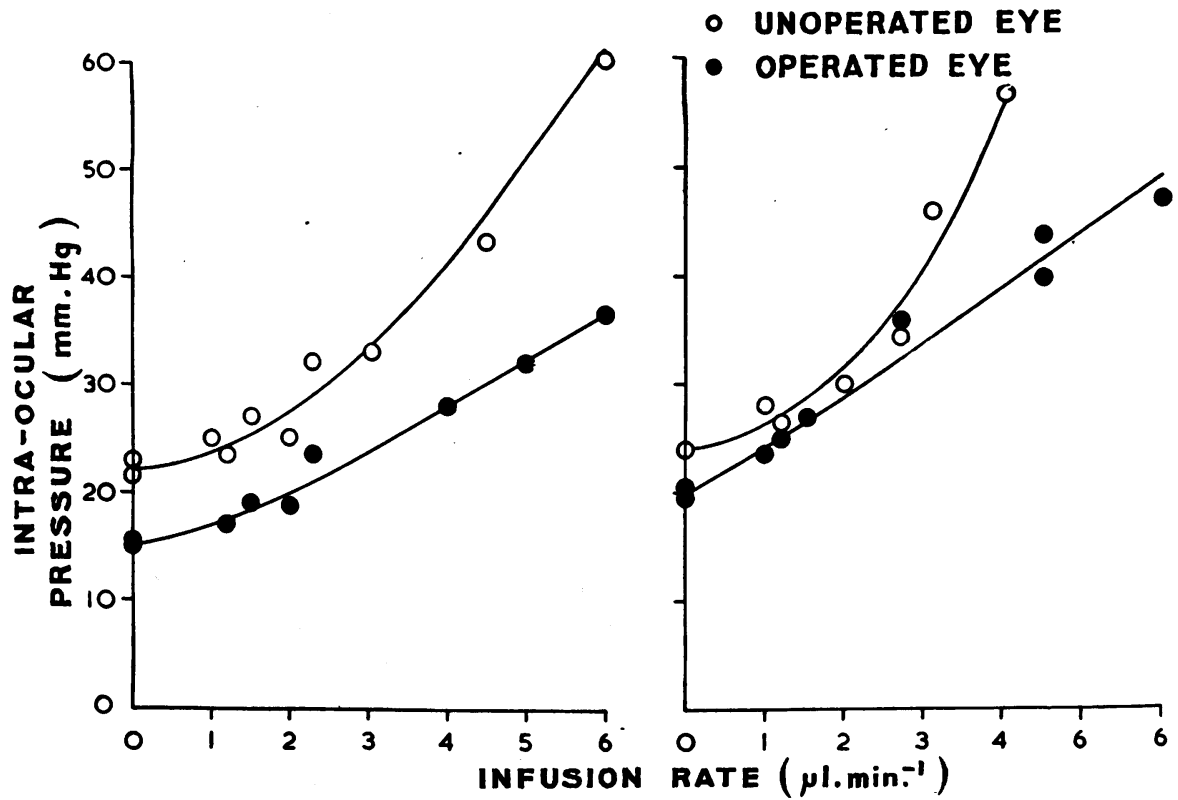

FIG. 11.-Relationship between steady state intra-ocular pressure and infusion rate in rabbits $24 \mathrm{hrs}$ after unilateral carotid ligation.

The immediate effect of section of the nerve was studied in three rabbits, two of the results being recorded in Fig. 12 (overleaf). In all three rabbits section of the nerve caused no change in the intra-ocular pressure, but the results of infusion studies in experimental eyes were significantly different from those in control eyes. The steady state intra-ocular pressure in the experimental eyes was found to increase proportionately with the rate of infusion of saline phosphate into the anterior chamber. In two of these rabbits the slope of the curve exceeded that in the control eye, while in the third eye the slope was significantly less. Analysis of the aqueous humour of these rabbits showed that, in the first two, the protein content of the experimental eyes much exceeded that in the control eyes, while in the third rabbit the aqueous humour in both eyes was non-plasmoid. 
(a)

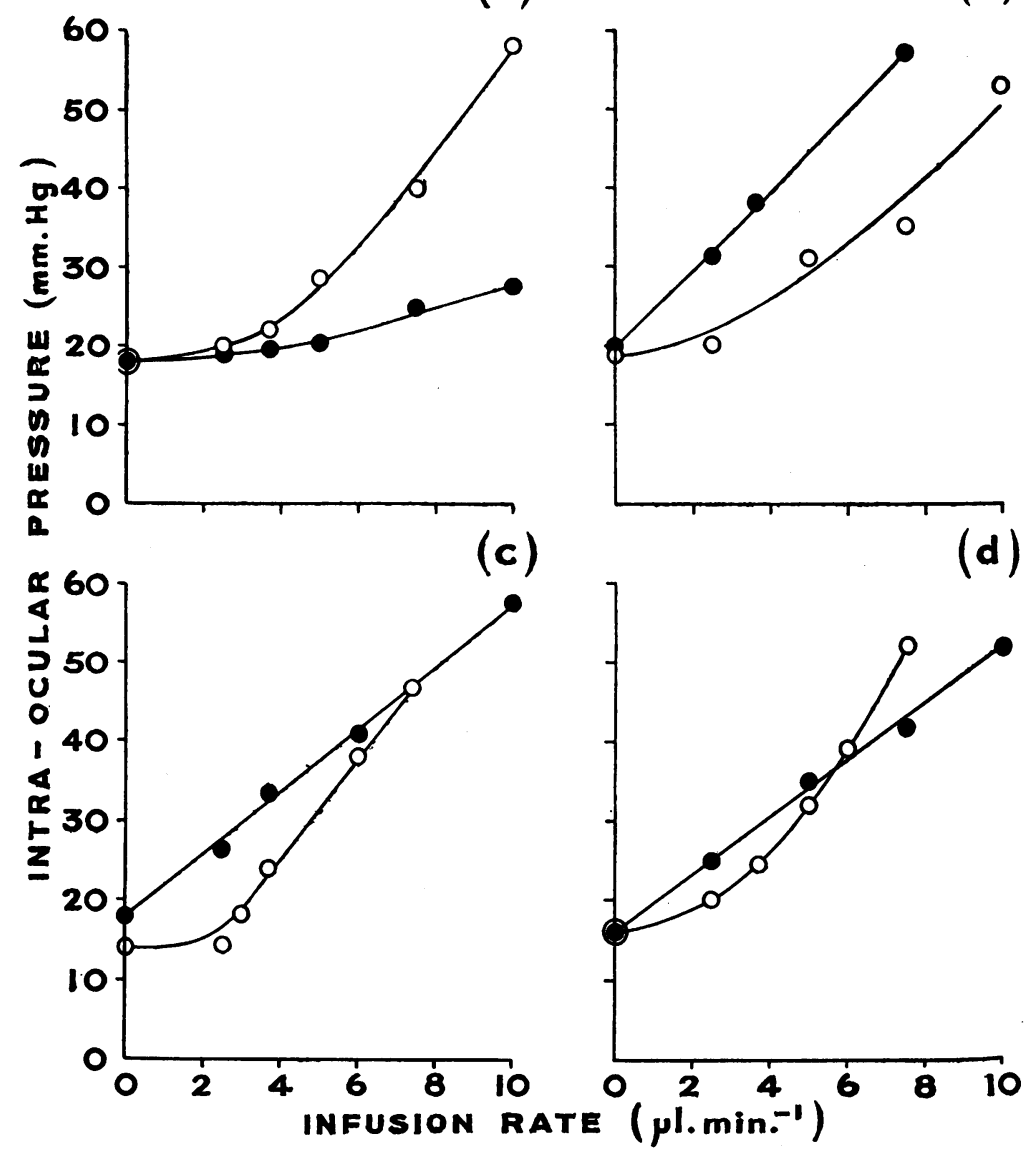

(b)

Fig. 12.-Effect of preganglionic cervical sympathotomy on relationship between steady state intra-ocular pressure and infusion rate in anaesthetized rabbits.

$(a)$ and $(b)$ Records made on eyes before $(\mathrm{O}-\mathrm{O})$ and immediately after $(\bullet-\bullet)$ section of the nerve.

$(c)$ and $(d)$ Records made on control $(O-O)$ and experimental eyes (-- $) 24 \mathrm{hrs}$ after section of the nerve.

In four rabbits examined 24 hours after unilateral preganglionic cervical sympathotomy, the intra-ocular pressures in the control and experimental eyes were $20,19,21$, and $20 \mathrm{~mm} . \mathrm{Hg}$, and $20,21,19$, and $18 \mathrm{~mm}$. $\mathrm{Hg}$ respectively; the mean femoral blood pressure was $115 \mathrm{~mm}$. $\mathrm{Hg}$. The effect of different intra-ocular infusions on the control eyes was similar to that on normal eyes, but in the experimental eyes the intra-ocular pressure was again found to increase in a linear manner with the rates of infusion.

(d) Intra-ocular Injections of Hyaluronidase.-Recently, Bárány (1954) and Bárány and Scotchbrook (1954) have shown that the outflow resistance in the enucleated and living eye could be decreased by intra-ocular injections of hyaluronidase, and in the present experiments an attempt was made to 
assess how far the action of the enzyme on the outflow resistance would affect the relationship between the steady state intra-ocular pressure and different rates of infusion in living eyes.

The first experiments were made on freshly enucleated eyes to determine the enzyme activity needed to decrease the outflow resistance. One eye was used as a control and different concentrations of the enzyme were added to the perfusate for the second eye. A typical result of the fall in the outflow resistance after an intra-ocular injection of hyaluronidase in a dead eye is shown in Fig. 13.

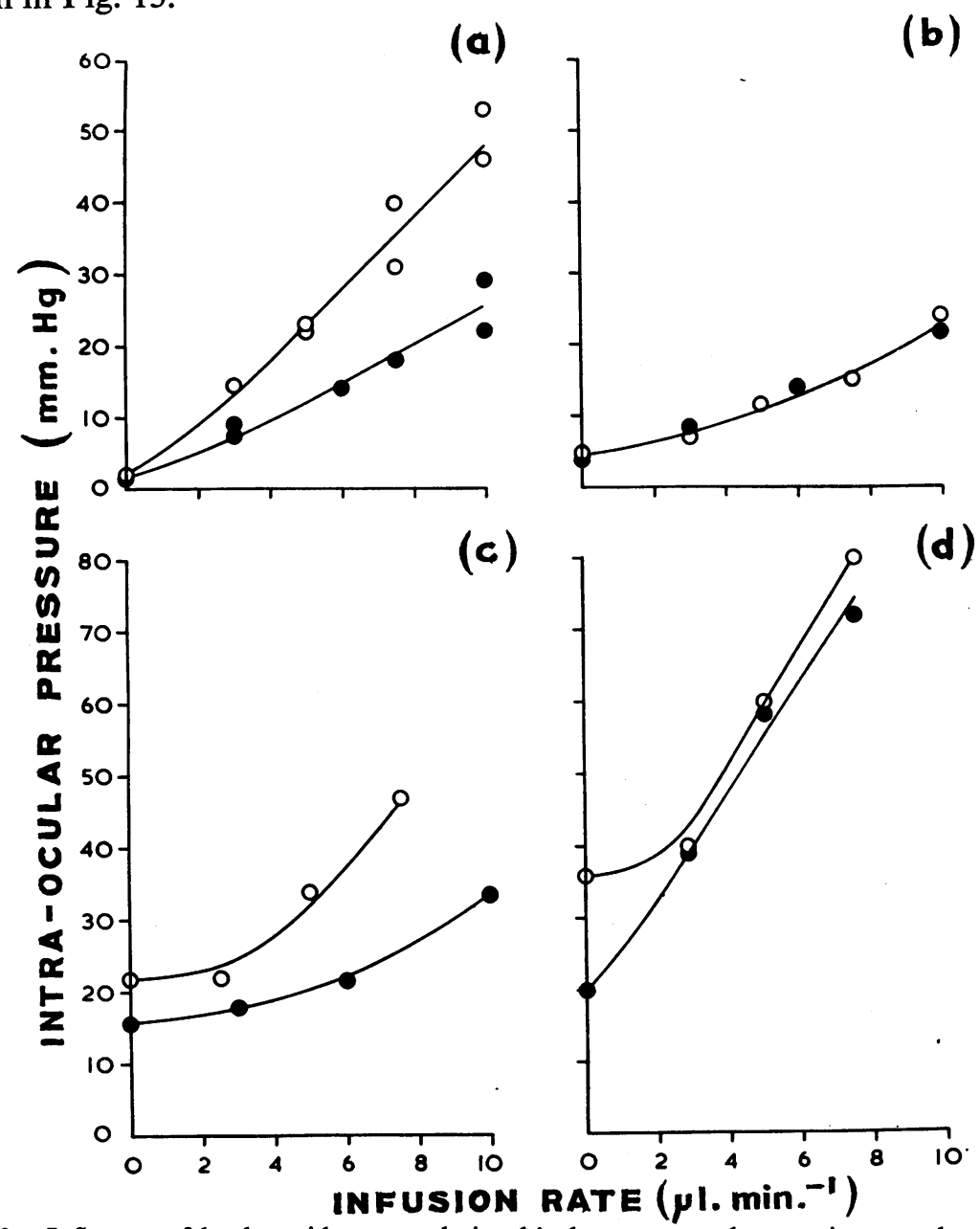

(b) and infusion rate in living and dead rabbit eyes.

(a) Results of infusions of saline phosphate $(\mathrm{pH} \mathrm{7.4)}$ into a freshly enucleated eye $(\mathrm{O}-\mathrm{O})$ and saline phosphate containing 50 V.R.U. hyaluronidase $/ \mathrm{ml}$. into the second eye ( $-\bullet)$.

(b) Comparison of the action of saline phosphate containing 5 V.R.U./ml. (O-O) and 50 V.R.U./ml. (—) of hyaluronidase.

(c) and $(d)$ Infusion studies on a normal living eye $(\mathrm{O}-\mathrm{O})$ and the eye of the same animal after mixing hyaluronidase with the aqueous humour of the anterior chamber to give a final concentration of approximately 10 V.R.U./ml. (•-๑). 
These results are in agreement with Bárány's observations that the rate of flow of fluid from the anterior chamber increased approximately 100 per cent. after injection of hyaluronidase. In further experiments it was found that a concentration of 5 Viscosity Reducing Unit ml.-1 (V.R.U.) in the anterior chamber was sufficient to cause a maximal reduction in the outflow resistance (see Fig. 13); lower concentrations still affected the outflow resistance, but the reaction took up to $30 \mathrm{~min}$. for completion.

On the basis of these experiments, initial studies on the living rabbit were made with saline phosphate containing 5 V.R.U. hyaluronidase $\mathrm{ml}^{-1}$, but this was found to be insufficient to affect the eye. In four further experiments, sufficient hyaluronidase was mixed directly with the aqueous humour of the anterior chamber to give a final concentration of approximately 10 V.R.U. $\mathrm{ml}^{-1}$, and this did cause a decrease in the intra-ocular pressure. Unfortunately, this concentration of hyaluronidase also caused a rapid increase in the permeability of the blood-aqueous barrier to protein, and the intraocular pressure became unstable. Evidence, however, that hyaluronidase caused a marked decrease in outflow resistance was found in two of the four treated eyes, and one of these results is recorded in Fig. 13(c).

The results in the other two treated eyes were similar; the pressure infusion curve in one of these eyes is shown in Fig. 13(d). In this experiment the infusion study was begun $20 \mathrm{~min}$. after the intra-ocular injection of hyaluronidase. The aqueous humour removed at the end of the experiment was plasmoid, but the result is of some interest because the basal intra-ocular pressure increased by only $2 \mathrm{~mm}$. $\mathrm{Hg}$ during the experimental period. It will be seen that the pressure/infusion relationship under these conditions was linear.

\section{Discussion}

Normal Intra-ocular Pressure.-Previous knowledge of the intra-ocular pressure has been based almost entirely on the indirect measurement of tonometry. In this procedure the pressure is evaluated from the degree of corneal indentation induced by a standard plunger resting on the cornea. By the use of calibration scales the tonometric reading is translated into units of absolute pressure. The limitation of this technique arises from the serious difficulties in obtaining valid calibration scales, and, although the relationship between corneal indentation of a standardized tonometer and pressure in human eyes has been extensively studied, there is still some doubt as to the accuracy of published curves (Friedenwald, 1948, 1954; Kronfeld, 1958). In rabbits attempts to calibrate tonometric readings with pressure have been made by Bliedung (1923) and Bárány (1947a), who found that the calibrations for rabbit eyes differed from those for human eyes and also that there was a difference between the living and dead eyes of the same animals. Neither Bliedung nor Bárány calculated the mean intra-ocular pressure of the rabbits used in their studies, but from experimental results 
quoted in Bárány's Table 6 the writer has calculated that the mean pressure of seven conscious rabbits was $27 \cdot 5 \pm 0.26 \mathrm{~mm}$. $\mathrm{Hg}$. This value is significantly higher than those reported in more recent studies in which the authors have used calibration scales published for human eyes. Thus Schmerl and Steinberg (1949) reported the mean intra-ocular pressure of nineteen conscious rabbits to be $24 \cdot 0 \pm 0 \cdot 61 \mathrm{~mm}$. $\mathrm{Hg}$, using the 1948 Schiötz tonometric tables, and Stone and Prijot (1955) reported the mean intra-ocular pressure of conscious rabbits to be $23 \cdot 0 \pm 1 \cdot 23(10)$, using the 1954 revised tonometric tables (Friedenwald, 1954). If the observations of these two groups of workers are transposed to the scales for rabbit eyes published by Bárány, the mean intra-ocular pressures increase to 28 and $29 \mathrm{~mm}$. $\mathrm{Hg}$.

In view of the uncertainty in calculating absolute pressures by tonometry, it is difficult to say whether the pressures measured manometrically in this study differ significantly from the pressures found in conscious animals. However, a close estimate of the absolute pressure in the conscious rabbit may be obtained by using the results published by Stone and Prijot (1955) on the effect of anaesthesia on the intra-ocular pressure of individual rabbits. In tonometric studies they reported that the mean intra-ocular pressure in six rabbits anaesthetized with Nembutal was $85 \cdot 5 \pm 5 \cdot 8$ per cent. of that in conscious animals; this represented a fall of approximately $3 \mathrm{~mm}$. $\mathrm{Hg}$. Now the mean intra-ocular pressure of rabbits anaesthetized with Nembutal and measured manometrically in the present studies was $17 \cdot 2 \pm 0.63 \mathrm{~mm}$. $\mathrm{Hg}$, and on this basis the intra-ocular pressure of conscious rabbits should be 20 to $21 \mathrm{~mm}$. Hg. This pressure corresponds to the mean intra-ocular pressure of $20.6 \pm 0.57 \mathrm{~mm}$. $\mathrm{Hg}$ found in rabbits anaesthetized with Urethane; it would be of interest to see whether Urethane influences tonometric readings in rabbits.

The pressure of 20 to $21 \mathrm{~mm}$. Hg for the eyes of conscious rabbits agrees closely with the value accepted many years ago for human eyes. Cridland (1917) reported a mean intra-ocular pressure of $20.06 \mathrm{~mm}$. $\mathrm{Hg}$ in a series of 1,000 normal eyes, and Glees (1952) recently reported that the average intra-ocular pressure of 5,392 normal human eyes was $20 \cdot 3 \mathrm{~mm}$. Hg. However, because of revisions of the calibration scales for the Schiötz tonometer, the mean intra-ocular pressure is now believed to be 15 to $16 \mathrm{~mm}$. $\mathrm{Hg}$. A similar value was found by Goldmann (1957) using an applanation tonometer of new design. On the other hand,Maurice (1958), using an indentation tonometer with a very small volume displacement, reported the mean pressure in humans to be $19 \mathrm{~mm}$. $\mathrm{Hg}$, and Estrada (1958), in a manometric study of a series of patients, also calculated the mean intra-ocular pressure to be $19 \mathrm{~mm}$. Hg.

Influence of Intra-ocular Pressure on Aqueous Humour Formation and Outflow Resistance.--It is helpful to consider the results of the infusion studies on the basis of the hydrodynamics of the outflow process. The rate of outflow $F\left(\mu 1\right.$. min. $\left.^{-1}\right)=\left(P_{o}-P_{v}\right) C$, where $P_{o}$ and $P_{v}$ are the pressures in the 
anterior chamber and the episcleral veins respectively, and $C$ is the outflow facility $\left(\mu 1 .(\mathrm{mm} . \mathrm{Hg})^{-1} \mathrm{~min}^{-1}\right)$. In the present infusion studies, $P_{o}$ was found to be $21.3 \mathrm{~mm}$. Hg, and Kornbluth and Linnér (1955) have reported that the mean value of $P_{v}$ in rabbits was $8.9 \mathrm{~mm}$. $\mathrm{Hg}$. The absolute rate of flow of aqueous humour in these rabbits is not known, but would lie between 2 and $4 \mu \mathrm{l}$. min. ${ }^{-1}$ on the assumption that the flow was 1 to 2 per cent. $\min .^{-1}$. If these values are substituted in the above equation, $C$ equals 0.175 to $0.35 \mu 1$. (mm. Hg) $)^{-1}$ min. $^{-1}$

The influence of increased flow on the intra-ocular pressure has been calculated on the assumption that $C$ and $P_{v}$ remain constant; the results are expressed in Fig. 14 and for comparison the observations on the living animal have been included. It will be seen that the experimental curve differs from the two theoretical curves in showing positive curvature. This means that $C, P_{v}$, or $F$ must vary with pressure. Furthermore, it is evident that changes in these parameters took place for pressure increments of less than $10 \mathrm{~mm}$. $\mathrm{Hg}$, which is the minimal initial pressure increment observed during tonographic studies.

The argument in support of the assumption made in tonographic calculations, that moderate changes in pressure do not significantly influence aqueous humour formation or outflow resistance, has been based on indirect experimental evidence. Grant (1950) studied the volume changes when a tonometer with different weights was placed on the eye, and calculated that there was an approximate linear relationship between the pressure increment and the rate of loss of volume of the eye. In later studies, Grant and Trotter (1955) reported that outflow facility measured tonographically in living eyes was similar to that estimated from perfusion studies of dead eyes. Although these results are consistent with the assumption that pressure does not significantly change aqueous humour formation and outflow resistance, the difficulties in interpreting such results became evident from a series of tonographic studies of eyes of normal subjects by Goldmann (1955). The results of these experiments, summarized in Table III (opposite), show that the calculated value of the outflow facility in individual eyes decreased as the tonometric load was increased from 5 to $15 \mathrm{~g}$. These observations are consistent with the evidence found in the present studies that pressure influences aqueous humour formation and outflow resistance, but Goldmann at that time attributed the change in facility to the elastic properties of the eye.

Recently, however, Goldmann (personal communication) has reconsidered this interpretation in the light of further experimental studies and has now concluded that, in addition to changes in the elastic properties of the eye, the increased pressure causes a decrease in the rate of aqueous humour formation.

On the other hand, further experimental evidence supporting the view that moderate changes in intra-ocular pressure do not influence aqueous humour formation and outflow resistance is to be found in the studies of Becker and Constant (1956). 
TABLE III

\section{CHANGE IN OUTFLOW FACILITY WITH DIFFERENT TONOMETRIC} WEIGHTS IN TWENTY NORMAL EYES

The middle column shows the initial intra-ocular pressure immediately after the application of the tonometer to the eye

\begin{tabular}{c|c|c}
\hline $\begin{array}{c}\text { Tonometric Load } \\
(\mathrm{g} .)\end{array}$ & $\begin{array}{c}\text { Initial Intra-ocular Pressure } \\
(\mathrm{mm} . \mathrm{Hg})\end{array}$ & $\begin{array}{c}\text { Outflow Facility } \\
\left(\mu \mathrm{l} .(\mathrm{mm} . \mathrm{Hg})^{-1} \mathrm{~min}^{-1}\right)\end{array}$ \\
\hline & & \\
0.0 & $14 \cdot 0 \pm 0 \cdot 41$ & $0 \cdot 230 \pm 0.012$ \\
5.5 & $25 \cdot 4 \pm 0 \cdot 38$ & $0 \cdot 153 \pm 0 \cdot 007$ \\
10.0 & $36 \cdot 2 \pm 0.64$ & $0 \cdot 144 \pm 0 \cdot 007$ \\
\hline 15.0 & $47 \cdot 1 \pm 0 \cdot 37$ & \\
\hline
\end{tabular}

A hypodermic needle connected by polythene tubing to a pressure reservoir was introduced into the anterior chamber, and the rate of inflow of saline was measured for different pressure heads. Under these conditions the relationship of pressure and rate of inflow of fluid was found to be approximately linear, and was assumed to be a measure of the outflow resistance. In a study of 28 rabbit eyes, Becker and Constant calculated that the outflow facility measured tonographically was $0.33 \pm 0.02 \mu \mathrm{l}$. (mm. Hg) ${ }^{-1}$ min..$^{-1}$, and in the same rabbits they found that the outflow facility measured by the perfusion technique before and after death was $0.34 \pm 0.02$ and $0.37 \pm 0.02 \mu 1$. $(\mathrm{mm} . \mathrm{Hg})^{-1} \mathrm{~min}^{-1}$ respectively. The close agreement between the results of the three series of experiments was regarded as convincing evidence of the validity of the tonographic technique in measurements of aqueous humour dynamics.

Theoretically, the relationship between the steady state intra-ocular pressure and the rates of infusion into the anterior chamber could be explained by a change in episcleral venous pressure, aqueous humour formation, or outflow resistance. The large rise in episcleral venous pressure which would be necessary to account for the observed curve (Fig. 14a, overleaf) appears most unlikely in view of the observation that the episcleral venous pressure increases no more than 1 to $2 \mathrm{~mm}$. $\mathrm{Hg}$ when a tonometer is placed on the eye (Linnér, 1955). If only the outflow resistance changed with pressure it would be possible to account for the observed results by an increase or a decrease in resistance depending on the value accepted for the rate of aqueous humour formation (see Fig. 14a). If we accept the limits of aqueous humour formation as 2 to $4 \mu \mathrm{l}$. min. $^{-1}$, it is evident that for low infusion rates the outflow resistance falls below normal, while an upward trend of the pressure/infusion curve at higher infusion rates indicates a marked increase in outflow resistance. Although no evidence was found in dead eyes that pressure influences outflow resistance, support for this interpretation may be found in the recent studies of Goldmann (1957), who found the 

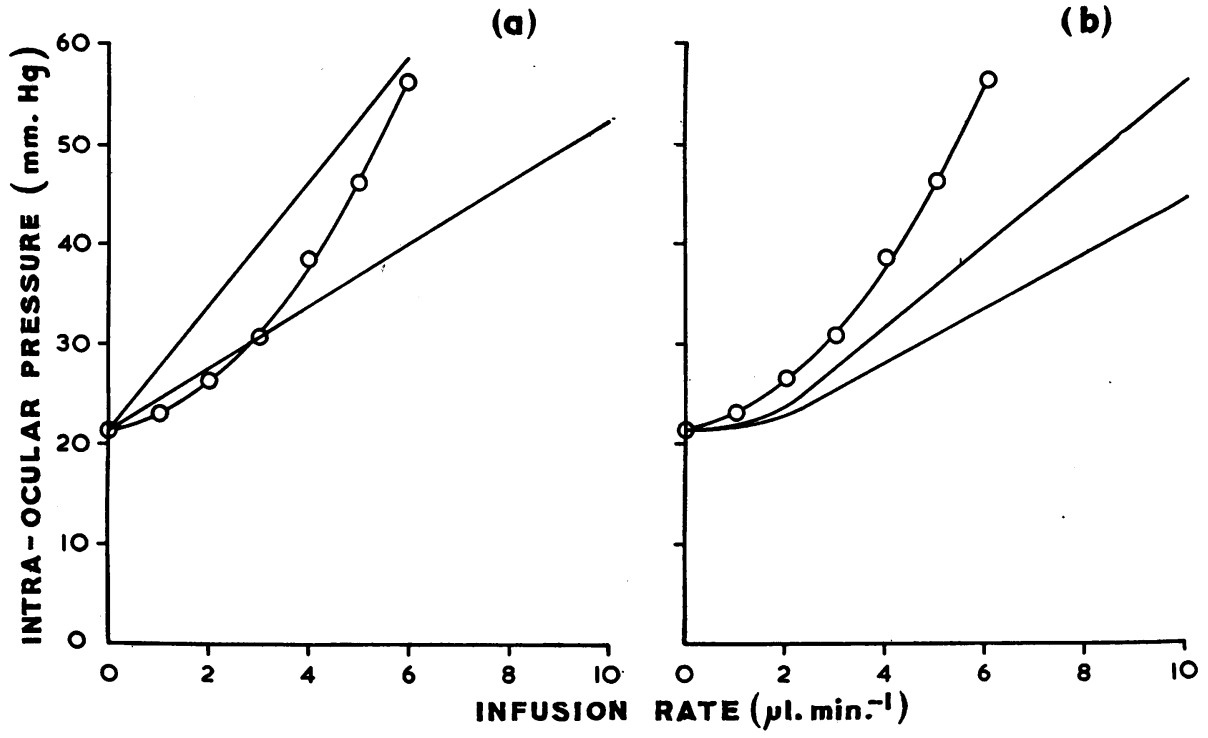

Fig. 14.-Influence of aqueous flow on steady state intra-ocular pressure.

(a) Upper and lower straight lines calculated on the assumption that the normal rate of flow of aqueous humour was 2 and $4 \mu \mathrm{l}$. min. ${ }^{-1}$ respectively, using the equation $P_{0}=F / C+P_{v}$, where $\boldsymbol{P}_{v}$ is constant and the normal intra-ocular pressure is $21 \cdot 3 \mathrm{~mm}$. $\mathbf{H g}$.

(b) The normal rate of aqueous humour formation has been assumed to be $3 \mu \mathrm{l} . \mathrm{min}^{-1}$, and the two lines show the pressure infusion relationship when either aqueous humour formation (upper line) or outflow resistance (lower line) falls by 50 per cent. when the infusion rate is $2 \mu \mathrm{l}$. min. ${ }^{-1}$.

In both $(a)$ and $(b)$ the mean curve found in living animals is included $(\mathrm{O}-\mathrm{O})$.

pressure in the aqueous veins of individual eyes to increase by $10 \mathrm{~mm} . \mathrm{Hg}$ when the intra-ocular pressure rose by 30 to $40 \mathrm{~mm}$. $\mathrm{Hg}$; this means that the pressure gradient between the aqueous and episcleral veins increases with the intra-ocular pressure, since the episcleral venous pressure is nearly constant under these conditions.

The observed pressure/infusion curve could also be explained as being due to a decrease in aqueous humour formation for the low rates of infusion. Experimental support for this explanation has been found in direct measurements of aqueous humour formation at different pressures (Langham, 1959). For higher infusion rates it would however be necessary to assume that aqueous humour formation increases above normal if the outflow resistance is constant. This, however, cannot be so, for (as stated above) aqueous humour formation has been shown to decrease with pressure; it is therefore necessary to conclude that outflow resistance does increase at higher pressures.

To summarize, it would appear probable that both parameters vary with pressure and that the resultant pressure/infusion curve is determined principally by a decrease in aqueous humour formation or outflow resistance 
for small increases in intra-ocular pressure, and an increase in outflow resistance for pressures well above the normal physiological range.

From the average pressure/infusion curve in living animals it is possible to estimate the error involved in measuring outflow resistance by the tonographic technique if the effect of the tonometer weight on aqueous humour formation and outflow resistance is neglected. In a normal eye, the tonometer $(5.5 \mathrm{~g}$.) causes an initial increase of 10 to $15 \mathrm{~mm}$. $\mathrm{Hg}$ in the intra-ocular pressure and in this pressure range the results of infusion studies indicate that the estimate of outflow resistance or of the rate of aqueous humour formation could err by at least 50 per cent.

Regulation of the Intra-ocular Pressure.-The question whether the relationship in normal eyes between the steady state intra-ocular pressure and infusions reflects the ability of pressure to induce compensatory changes in aqueous humour formation or in outflow resistance is of fundamental importance to our understanding of the regulation of the pressure in the eye. A linear relationship between pressure and infusions would argue strongly against the presence of homeostatic reactions in the eye, and it was therefore of particular interest that this relationship in normal eyes showed positive curvature. To throw further light on this problem infusion studies were made in eyes in which the normal intra-ocular dynamics had been modified. It was considered that a change in intra-ocular dynamics would be a stimulus to the homeostatic mechanism and that this would modify the positive curvature of the pressure/infusion relationship, if this curve was in fact evidence of homeostasis. On the other hand, if the positive curvature simply reflected an increased outflow resistance at higher pressure, it was thought that this curvature was unlikely to be modified by specific effects on aqueous humour dynamics.

The results of the infusion studies not only gave strong support to the view that compensatory reactions take place in the eye, but also indicated that these reactions were dependent on an intact sympathetic supply to the eye. The injection of acetazoleamide (which acts specifically in inhibiting the rate of secretion of aqueous humour without affecting the general blood supply to the eye) resulted in a linear relationship between pressure and infusion. At the same time, unilateral ligation of the common carotid artery (which causes changes in blood flow and vascular pressures in the eye, but has little immediate effect on intra-ocular dynamics: Bárány, 1947b; Davson and Matchett, 1951) caused no immediate decline in the normal pressure/ infusion relationship. However, 24 hours after the operation, at which time a marked change in the rate of aqueous humour formation and outflow resistance has been reported (Kornbluth and Linnér, 1955), the pressure/infusion relationship was found to be linear: Thus it appears that the initial slope of the pressure/infusion curve is a specific characteristic of the normal eye. Furthermore, the increased slope of the curve, which is 
seen when the intra-ocular dynamics are significantly altered, strongly suggests that in the normal eye an increase in pressure causes a decrease either in aqueous humour formation or in outflow resistance, or in both.

The observation that the pressure/infusion curve in normal eyes was dependent on an intact sympathetic supply is of considerable physiological interest, for it might well indicate that the homeostatic responses in normal eyes are mediated through neural reflexes. In this connexion the recent findings of von Sallmann, Fuortes, Macri, and Grimes (1958) of a synchronous relationship between the electrical activity in the long and short ciliary nerves and the intra-ocular pressure suggest that pressure receptors may be present in the eye and that the ciliary nerves form the afferent portion of such a neural reflex. At the same time, the known influence of sympathetic nervous activity on intra-ocular dynamics indicates that this nerve could constitute the efferent pathway of the reflex, for not only does electrical stimulation cause changes in aqueous humour formation (see Langham, 1958a), but also the excision of the superior cervical ganglion has been reported to lower the outflow resistance in rabbit eyes (Langham and Taylor, 1959). The presence of a neural reflex of this nature in the eye must however remain speculative until more is known of the function of central nervous activity in regulating the intra-ocular pressure. This aspect of the problem has received much attention in recent years (von Sallmann and Lowenstein, 1955; von Sallmann, 1956; Gloster and Greaves 1956, 1957), but still remains largely unresolved.

\section{Summary}

(1) The object of this study was to determine the effect of the intra-ocular pressure on the formation and the resistance to outflow of the aqueous humour, and to assess how far these two processes participate in regulating the pressure in the eye.

(2) As a basis to these studies, manometric measurements were made of the intra-ocular pressure in normal living rabbits and in rabbit eyes 15 to $20 \mathrm{~min}$. after death. Animals anaesthetized with Nembutal were found to have a slight but significantly lower intra-ocular pressure than those anaesthetized with Urethane. The mean intra-ocular pressure of rabbits anaesthetized with Urethane was $20 \cdot 6 \pm 0.57(26) \mathrm{mm}$. $\mathrm{Hg}$, and reasons are put forward for the belief that this pressure corresponds closely to the mean pressure in conscious rabbits. After death the intra-ocular pressure was found to fall to a limiting mean value of $7.0 \mathrm{~mm}$. $\mathrm{Hg}$.

(3) The relationship between the intra-ocular pressure and different rates of infusion of fluid into the anterior chamber of living and dead rabbit eyes has been established. In the eyes of freshly-killed animals, the steady state pressure was found to increase proportionately with the rates of infusion of 
fluid over a pressure range of 5 to $50 \mathrm{~mm}$. Hg. In the living animal, however, the pressure/infusion relationship showed a positive curve. The results indicated that aqueous humour formation, outflow resistance, and episcleral venous pressure did not all remain constant when the intra-ocular pressure rose. An analysis of the curve suggests that, as the intra-ocular pressure increased, there was a decrease in either aqueous humour formation or in outflow resistance, and that the maximal response corresponded to a decrease in aqueous humour formation of aproximately 2 to $3 \mu 1 . \mathrm{min}^{-1}$ or to a decrease in the outflow resistance of approximately 50 per cent.

(4) Records of pressure in the contralateral eye during infusion studies were made, but no evidence was found of any contralateral reaction.

(5) The results of the infusion studies of living eyes were consistent with the concept that the regulation of the intra-ocular pressure involves homeostatic reflexes which modify either aqueous humour formation or outflow resistance. An attempt was made to analyse this possibility from a study of eyes in which the intra-ocular dynamics had been modified. These included:

(a) intravenous injection of acetazoleamide,

(b) unilateral ligation of the common carotid artery,

(c) section of the preganglionic cervical sympathetic fibres,

(d) intra-ocular injections of the enzyme hyaluronidase.

It was found that the sympathetic fibres to the eye were essential for the response of the normal eye to different infusions. The results also indicated that the normal response of the eye was significantly reduced by the above procedures.

(6) The significance of these results is discussed in relation to the problem of the control of the intra-ocular pressure and to the practical problem of measuring outflow resistance and of aqueous humour formation by the tonographic technique. It is suggested that the action of a raised intra-ocular pressure in decreasing the formation or outflow resistance of the aqueous humour does form part of the mechanism by which changes in intra-ocular pressure are minimized. Furthermore, this evidence leads to the belief that the technique of tonography does not give a measure of the outflow resistance in the untouched eye.

I wish to express my sincere thanks to Prof. D. C. Cogan, Prof. M. Grant, and Sir Stewart Duke-Elder for their continued interest and advice. I am indebted to the Alfred P. Sloan Foundation, and the Medical Research Council, England, for the equipment used in this study. 


\section{REFERENCES}

BÁRÁNY, E. H. (1947a). Acta ophthal. (Kbh.), $25,81$. (1947b). Acta physiol. scand., 13, 55.

(1954). Acta Soc. Med. upsalien., 59, 260.

and SCOTCHBROOK, S. (1954). Acta physiol. scand., 30, 240.

BECKER, B. (1955). Amer. J. Ophthal., 39, No. 2, pt 2, p. 177. and Constant, M. A. (1956). A.M.A. Arch. Ophthal., 55, 305. and Middleton, W. H. (1955). Ibid., 54, 187.

BlIEDUNG, C. (1923) Arch. Augenheilk., 92, 143.

CRIDLAND, B. (1917). Brit. J. Ophthal., 1, 352.

DAVson, H., and MATCHETt, P. A. (1951). J. Physiol. (Lond.), 113, 387.

DUKE-ELDER, S. (1927). Ibid., 64, 78.

EsTrADA, A. T. (1958). Actualités Latines d'Ophtalmologie, 1, 160.

FriEdENWALd, J. S. (1948). Amer. J. Ophthal., 31, 935. (1954). "Decennial Committee on Standardization of Tonometers", Trans. Amer. Acad. Ophthal. Otolaryng., Suppl. Chapter VII.

GleEs, M. (1952). v. Graefes Arch. Ophthal., 153, 356.

Gloster, J., and Greaves, D. P. (1956). Proc. roy. Soc. Med., 49, 675. (1957). Brit. J. Ophthal., 41, 513.

GoldmanN, H. (1955). In "Glaucoma. A Symposium”, ed. S. Duke-Elder, p. 105, Blackwell, Oxford.

(1957). "Applanation Tonometry", in "Trans. II Conf. Glaucoma", ed F. W. Newell, p. 167. Josiah Macy Jr. Foundation, New York.

Grant, W. M. (1950). Arch. Ophthal. (Chicago), 44, 205.

(1951). A.M.A. Arch. Ophthal., 46, 113. and TROTTER, R. R. (1955). Ibid., 53, 191.

GUERRY, D. (1951). Trans. Amer. ophthal. Soc., 49, 525.

Henderson, E. E., and Starling, E. H. (1904). J. Physiol. (Lond.), 31, 305.

KorNBLUTH, W., and LINNÉR, E. (1955). A.M.A. Arch. Ophthal., 54, 717.

KRONFELD, P. C. (1958). Amer. J. Ophthal., 45, 308.

LANGHAM, M. E. (1958a). Physiol. Rev., 38, 215. (1958b). Brit. J. Ophthal., 42, 577. (1959). J. Physiol. (Lond.), 147, 29 P.

— and LEE, P. M. (1957). Brit. J. Ophthal., 41, 65.

LEBER, T. (1876). In "Graefe-Saemisch Handbuch der gesamten Augenheilkunde", vol. 2, p. 371. Engelmann, Leipzig.

LINNÉR, E. (1955). “Acta XVII Conc. Ophthal.”, vol. 3, pp. 1532-33. and PriJot, E. (1957). A.M.A. Arch. Ophthal., 58, 77.

MAURICE, D. M. (1958). Brit. J. Ophthal., 42, 321.

NIESNAMOFF, E. (1896). v. Graefes Arch. Ophthal., 42, pt. 4, p. 1.

Priot, E. L., and Stone, H. H. (1956). Amer. J. Ophthal., 42, 50.

von SAllman, L. (1956). "Central Control of Intra-Ocular Pressure", in "Trans. I Conf. Glaucoma”, ed. F. W. Newell, p. 81. Josiah Macy Jr. Foundation, New York.

, FuORTES, M. G. F., MACRI, F. J., and GrImEs, P. (1958). Amer. J. Ophthal., 45, pt. 2, p. 211.

and Lowenstein, O. (1955). Ibid., 39, No. 4, pt. 2, p. 11.

SCHMERL, E., and STEINBERG, B. (1949). Ibid., 35, 469.

STOCKER, F. (1887). v. Graefes Arch. Ophthal., 33, pt. 1, p. 105.

Stone, H. H., and PriJot, E. L. (1955). A.M.A. Arch. Ophthal., 54, 834.

WesSELY, K. (1908). Arch. Augenheilk., 60, 1. 